Research Article

\title{
DFT Calculations and Molecular Docking Studies on a Chromene Derivative
}

\author{
Najet Aouled Dlala $\left(\mathbb{D},{ }^{1}\right.$ Younes Bouazizi $\mathbb{D}^{2},{ }^{2}$ Houcine Ghalla, ${ }^{1}$ and Naceur Hamdi ${ }^{3}{ }^{3}$ \\ ${ }^{1}$ Quantum and Statistical Physics Laboratory, Faculty of Sciences, University of Monastir, Monastir, Tunisia \\ ${ }^{2}$ Heterocyclic Chemistry, Natural Products and Reactivity (LR11ES39) Laboratory, Faculty of Sciences, University of Monastir, \\ Monastir, Tunisia \\ ${ }^{3}$ Department of Chemistry, College of Science and Arts, Qassim University, Ar Rass, Saudi Arabia
}

Correspondence should be addressed to Naceur Hamdi; naceur.hamdi@isste.rnu.tn

Received 21 October 2020; Revised 3 March 2021; Accepted 21 March 2021; Published 1 April 2021

Academic Editor: Pasquale Longo

Copyright (C) 2021 Najet Aouled Dlala et al. This is an open access article distributed under the Creative Commons Attribution License, which permits unrestricted use, distribution, and reproduction in any medium, provided the original work is properly cited.

\begin{abstract}
Chromenes and their derivatives have been considered as an important class of oxygen-containing heterocycles. There has been an increasing interest in the study of chromenes due to their biological activity. Herein, the structural, electronic, and vibrational properties of a chromene derivative, entitled 2-amino-5-oxo-4-phenyl-4,5-dihydropyrano[3,2-c]chromene-3-carbonitrile and abbreviated as Chrom-D, have been reported. The FT-IR, UV-vis, and ${ }^{1} \mathrm{H}-\mathrm{NMR}$ and ${ }^{13} \mathrm{C}-\mathrm{NMR}$ chemical shifts' measurements were recorded. The molecular geometry and the vibrational frequencies are computed in the frame of density functional theory at the B3LYP/6-311++G(d,p) level of theory. The noncovalent interactions in the crystal lattice which are responsible to the 3D crystal structure of Chrom-D are investigated based on Hirshfeld surfaces and topological reduced density gradient (RDG) analysis. Molecular electrostatic potential surface, Mulliken charges, and Fukui functions are computed in order to find out the electrophilic and nucleophilic sites. The electronic properties of the title compound have been studied based on the TD-DFT calculations. Finally, Chrom-D has been evaluated as a multifunctional agent against Alzheimer's disease (AD).
\end{abstract}

\section{Introduction}

Since its discovery, heterocyclic chemistry was considered as one of the more complex areas of organic chemistry wherein heterocyclic compounds were considered as the largest family of organic compounds. Due to their structural diversity, heterocyclic compounds have proven their efficiency as therapeutic factors $[1-3]$. More specifically, heterocyclic molecules incorporating oxygen atoms are of particular interest. One of the most attractive classes of these materials is the class of chromene compounds, which presents a wide area of expertise for many scientists all over the globe.

Structurally, these compounds contain fused rings of pyran and benzene with different levels of saturation. From a pharmaceutical and medicinal point of view, chromene compounds were and remain considered as a fruitful area of investigation [4-8]. The fundamental aim of the molecular engineering of these materials was to improve their biological, medicinal, and pharmaceutical benefits.

Going deeper insight, relevant bibliographies focused on chromene compounds show that dihydropyrano[c]chromene and its derivatives are of a considerable interest because they possess a broad variety of biological properties, notably antifungal [9], antitumor [10], anti-HIV [11], antimicrobial, and antituberculous drugs [12], as well as muscle relaxants [13]. A series of synthetic dihydropyrano[c] chromene derivatives showed their significant pharmaceutical potential. More specifically, dihydropyrano[3,2-c] chromene and its derivatives are interesting heterocycles used for the treatment of neurodegenerative diseases such as amyotrophic lateral sclerosis, Alzheimer's, schizophrenia, and myoclonus [14].

Chrom-D, subject of the current report, is one of the most important derivatives of dihydropyrano[c]chromene. 
Its first synthesis was made in previous work by Bouazizi et al. in 2014 [15]. They showed that Chrom-D has antiacetylcholinesterase inhibitory activities. One year later, its X-ray crystal structure was determined by Sharma et al. [16]. They showed that Chrom-D crystallizes in the monoclinic $\mathrm{P} 2 / c$ space group with the following unit cell parameters: $a=9.0750(6) \AA, \quad b=13.2729(8) \AA, \quad c=12.6892(9) \AA$, $\beta=96.975(6)^{\circ}$, and $Z=4$.

To the best of our knowledge, neither DFT studies nor docking simulation has been reported yet for the Chrom-D compound. Based on these findings, it seems to be crucial to have a whole understanding of the Chrom-D molecule from a potential application point of view. For these reasons, we highlight the molecular structure, spectroscopic and population analysis, noncovalent interactions, and electronic and nonlinear optical properties for Chrom-D. Finally, molecular docking calculation was performed to estimate its antiacetylcholinesterase activity.

\section{Results and Discussion}

2.1. Synthesis. The basic pathway for the preparation of Chrom-D is reported in Figure 1. Further details are given in [15]. The first step of the compound identification was based on the analysis of ${ }^{1} \mathrm{H}-\mathrm{NMR}$ and ${ }^{13} \mathrm{C}$-NMR spectra. FT-IR spectroscopy was performed in the second step in order to identify and recognize its characteristic bands.

2.2. Structural Analysis. Figure 2(a) illustrates the asymmetric unit of the title compound. Its optimized geometry, with label atoms, is given in Figure 2(b). The structural parameters (bond lengths and angles) are listed in Table 1.

The experimental values are listed for comparison. The low root-mean-square deviation (RMSD) values of bond lengths $(0.074 \AA)$ and angles $\left(0.9^{\circ}\right)$ show a good agreement between the experimental geometry and the calculated one. The inspection of the structural parameters shows that all calculated $\mathrm{C}-\mathrm{H}$ and $\mathrm{N}-\mathrm{H}$ bonds are slightly larger than those obtained by X-ray diffraction. This deviation may be explained by the scattering factors of hydrogen atoms in the $\mathrm{X}$-ray diffraction. This fact can be interpreted by ignoring the intermolecular and Columbic interactions with the neighboring molecules in the crystal lattice.

As shown in Figure 2, Chrom-D molecule contains four rings: two pyran rings denoted $\mathrm{A}$ and $\mathrm{B}$ and two phenyl rings named $C$ and D. As discussed before [16], the dihedral angles between the mean plane of ring $\mathrm{A}$ and the rings $\mathrm{B}, \mathrm{C}$, and $\mathrm{D}$ are, respectively, $4.86(4)^{\circ}, 3.57(5)^{\circ}$, and $84.90(6)^{\circ}$. Also, we can easily notice that ring $\mathrm{D}$ is almost perpendicular to the general plane of these rings.

The mean bond lengths in the phenyl rings are experimentally 1.382 for C10-C11 and $1.373 \AA$ for C26-C27. These values were computed to be 1.393 and $1.397 \AA$ for C10-C11 and $\mathrm{C} 26-\mathrm{C} 27$, respectively.

The experimental bond length of the keto groupment $\mathrm{C} 7=\mathrm{O} 8$ is found to be $1.214 \AA$ which is comparable to the theoretical value $(1.213 \AA)$. These values are typical for double-bond distance. In similar vein, bond lengths of C2-
O1, C20-O1, C10-O9, and C7-O9 are found to be 1.369, $1.381,1.377$, and $1.377 \AA$, respectively. Their corresponding calculated values were $1.365,1.368,1.368$, and $1.383 \AA$. All the geometrical parameters of the studied compound are found to be in conformity with the structural data of similar compounds [17]. The calculation shows that Chrom-D has a high value of dipole moment equal to $11 \mathrm{D}$. One may conclude that the compound can present significant electronic and nonlinear optical properties. Figure 3 shows the crystal packing projected along the " $a$ "-axis. Obviously, the molecular arrangement of the Chrom-D crystalline packing reveals the presence of the hydrogen bonding $\mathrm{N}-\mathrm{H} \cdots \mathrm{O}$ and C-H...O network linking different molecules to each other.

Different views highlighting the intermolecular interactions are depicted in Figure 4. One may conclude that the crystal packing is really ensured by $\mathrm{N}-\mathrm{H} . \ldots \mathrm{N}, \mathrm{C}-\mathrm{H} \cdots \pi$, and $\pi$ $\cdots \pi$ interactions. Both hydrogen atoms of the amino group are involved in intermolecular hydrogen bonding sheets.

2.3. Hirshfeld Surface Analysis. Hirshfeld surface analysis is a suitable tool to investigate the intermolecular interactions within the crystal packing $[18,19]$. The main idea of the Hirshfeld surface is to delineate the space filled by a molecule in a crystal to segment the crystal electron density into molecular fragments.

In this context, at each point of an isosurface, two different types of distances $d_{e}$ and $d_{i}$ are defined, which express the distance from the point to the nearest nucleus external to the surface and the distance to the nearest nucleus internal to the surface, respectively. A three-dimensional molecular surface was created by delineating the normalized contact distance $d_{\text {norm }}$. $d_{\text {norm }}$ is defined as

$$
d_{\mathrm{norm}}=\frac{d_{i}-r_{i}^{\mathrm{vdW}}}{r_{i}^{\mathrm{vdW}}}+\frac{d_{e}-r_{e}^{\mathrm{vdW}}}{r_{e}^{\mathrm{vdW}}},
$$

where $r_{e}^{v d W}$ and $r_{i}^{v d W}$ are the Van der Waals (VdW) radii of the two atoms external and internal to the Hirshfeld surface. Hirshfeld surfaces of Chrom-D mapped with $d_{\text {norm }}$ and the shape index along with the " $a$ "- and " $c$ "-axis are displayed in Figure 5.

The intermolecular interactions within the Hirshfeld surface are represented with the color code. The contacts with distances equal to the sum of the $\mathrm{VdW}$ radii are shown in white color, and the contacts with distances shorter than and longer than $\mathrm{VdW}$ radii are represented as red and blue colors, respectively. The red spots appeared in the $d_{\text {norm }^{-}}$ mapped Hirshfeld surface indicate the $\mathrm{N}-\mathrm{H} \cdot . \mathrm{O}$ and $\mathrm{N}-\mathrm{H} \cdot \cdots \mathrm{N}$ intermolecular H-bonds.

The shape index is highly sensitive to very subtle changes in the surface shape. It indicates the electron density surface around the molecular interactions. The small range of light colors on the surface symbolizes a weaker and longer interaction other than hydrogen bonds. The presence of red and blue triangles on the surface of the shape index is a characteristic of $\pi \ldots \pi$ interactions. The $2 \mathrm{D}$ fingerprint plots provide all intra- and intermolecular contacts in the form of griddle colored areas in each of $d_{i}$ and $d_{e}$, as depicted in 


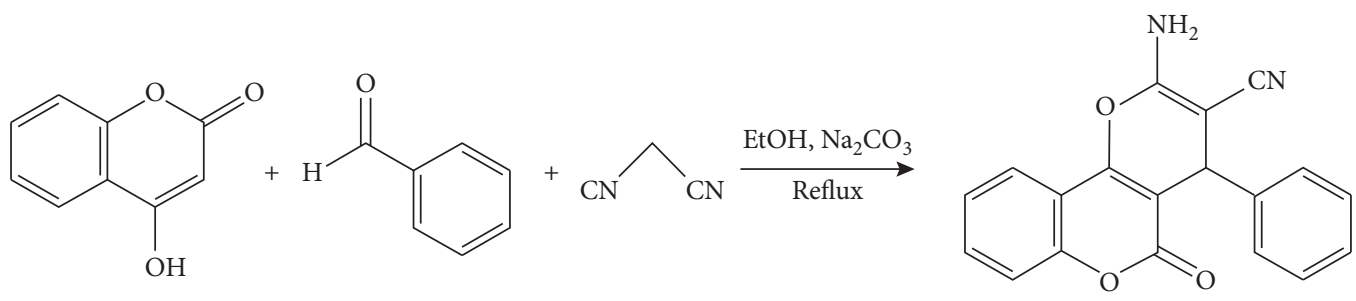

Figure 1: The synthesis pathway of the Chrom-D compound.

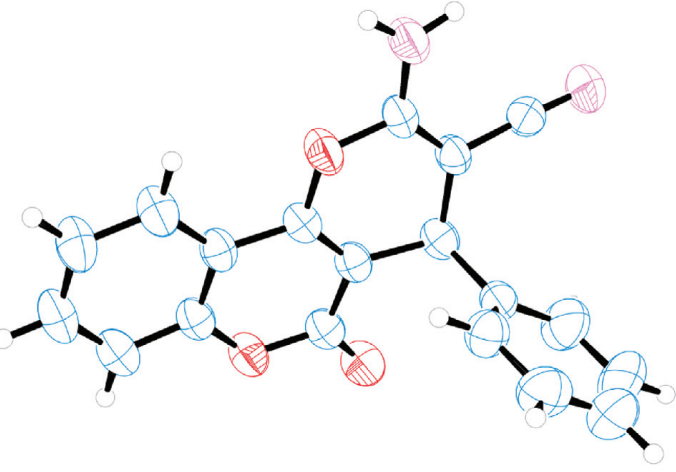

(a)

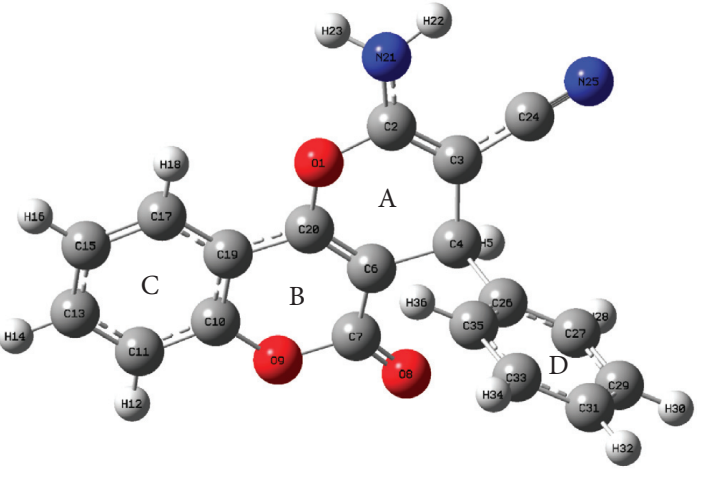

(b)

Figure 2: The molecular structure of Chrom-D (a) shown at 50\% ellipsoid probability and (b) optimized at the B3LYP/6-311++G(d,p) level of theory along with numbering of atoms ( $\mathrm{A}$ and $\mathrm{B}$ denote the pyran rings; $\mathrm{C}$ and $\mathrm{D}$ denote the phenyl rings).

Figure S1. Herein, the complete Hirshfeld surface indicates that the overall intermolecular interaction is maintained by H. ..H (37\%), H-C (18.6\%), H-O (18.5\%), and H-N (13.6\%) contact interactions. All interactions discussed above give rise to the formation of a $3 \mathrm{D}$ network of the Chrom-D compound.

2.4. RDG Analysis. The above analysis highlighted the intermolecular contacts giving rise to the stability of the crystalline packing. To deeply investigate the intermolecular interaction within the Chrom-D crystal, we have performed the noncovalent RDG analysis. This method is very popular for the investigation of weak interactions, such as hydrogen bond, VdW, and repulsive steric interactions using a simple color code. Blue, green, and red color codes indicate the presence of hydrogen bonding, VdW, and steric interaction, respectively. Further details for the RDG method are given in [20]. The RDG isosurfaces of the Chrom-D crystal are plotted in Figure 6.

As shown, the big flat isosurfaces, pointed by the red arrow, clearly indicate the $\pi-\pi$ stacking interactions. Moreover, all hydrogen bond interactions are appeared as filled-color green surfaces (as indicated by blue arrows). Furthermore, the RDG graph shows the presence of the intramolecular interaction in different positions highlighted with green color. Hence, we can conclude that these interactions can only be regarded like $\mathrm{VdW}$ interactions.

These findings lead to charge transfer between pyranbenzene of the first molecule and those of the second entity.
This delocalization is mainly caused by the tautomeric effect within each entity. The red isosurfaces figured within each ring correspond to the steric effect. All these results seem to be in a good matching with the structural data and HS analysis discussed previously.

2.5. Population Analysis. The molecular electrostatic potential (MEP) surface, Mulliken charges, and Fukui functions are calculated for the titled compound. MEP surface has been generated at the same level of theory and displayed in Figure 7.

This technique is a visual tool to envisage the electrophilic and nucleophilic behavior of the studied compound [21-24]. As shown in Figure 7, the negative regions, highlighted by red color, are laid around $\mathrm{C}=\mathrm{O}$ of ring $\mathrm{B}$ and $\mathrm{C} \equiv \mathrm{N}$ of ring A which may be explained by the tautomeric effects as well as their implication on the H-bonding network.

The positive region, highlighted by darkest blue color, appeared around the $\mathrm{NH}_{2}$ group of ring $\mathrm{A}$ which supports the formation of strong hydrogen bonding. Obviously, the nucleophilic and the electrophilic behaviors around the $\mathrm{C}=\mathrm{O}$ and $\mathrm{C} \equiv \mathrm{N}$ groups and $\mathrm{NH}_{2}$ group, respectively, support the presence of intermolecular interactions between different molecules forming the crystal packing.

The Mulliken charge distribution of Chrom-D has been carried out, and the values are given in Table S1. The highest positive and negative Mulliken charges are placed on carbon atoms C3 and C24, respectively. Amongst the $\mathrm{H}$-atoms, H22 and H23 have the highest Mulliken charge. Moreover, the 
TABle 1: Structural parameters of Chrom-D optimized at the B3LYP/6-311++G(d,p) level of theory compared to the experimental data.

\begin{tabular}{|c|c|c|c|c|c|}
\hline Bond length $(\AA)$ & B3LYP & $\operatorname{Exp}^{\mathrm{a}}$ & Bond angle $\left({ }^{\circ}\right)$ & B3LYP & $\operatorname{Exp}^{a}$ \\
\hline $\mathrm{R}(1,2)$ & 1.368 & 1.381 & $\mathrm{~A}(2,1,20)$ & 119.3 & 118.2 \\
\hline $\mathrm{R}(1,20)$ & 1.365 & 1.369 & $\mathrm{~A}(1,2,3)$ & 121.8 & 121.7 \\
\hline $\mathrm{R}(2,3)$ & 1.364 & 1.345 & $A(1,2,21)$ & 110.3 & 109.5 \\
\hline $\mathrm{R}(2,21)$ & 1.352 & 1.337 & $\mathrm{~A}(3,2,21)$ & 127.9 & 128.8 \\
\hline $\mathrm{R}(3,4)$ & 1.527 & 1.517 & $\mathrm{~A}(2,3,4)$ & 122.2 & 123.5 \\
\hline $\mathrm{R}(3,24)$ & 1.409 & 1.412 & $\mathrm{~A}(2,3,24)$ & 118.8 & 119.6 \\
\hline $\mathrm{R}(4,5)$ & 1.094 & 0.980 & $\mathrm{~A}(4,3,24)$ & 118.9 & 116.8 \\
\hline $\mathrm{R}(4,6)$ & 1.512 & 1.504 & $\mathrm{~A}(3,4,5)$ & 108.6 & 108.6 \\
\hline $\mathrm{R}(4,26)$ & 1.533 & 1.528 & A $(3,4,6)$ & 108.5 & 108.2 \\
\hline $\mathrm{R}(6,7)$ & 1.452 & 1.438 & A $(3,4,26)$ & 112.0 & 110.9 \\
\hline $\mathrm{R}(6,20)$ & 1.356 & 1.341 & $A(5,4,6)$ & 107.8 & 108.7 \\
\hline $\mathrm{R}(7,8)$ & 1.213 & 1.214 & A $(5,4,26)$ & 107.0 & 108.6 \\
\hline $\mathrm{R}(7,9)$ & 1.383 & 1.377 & $A(6,4,26)$ & 112.8 & 111.8 \\
\hline $\mathrm{R}(9,10)$ & 1.368 & 1.377 & $\mathrm{~A}(4,6,7)$ & 118.4 & 117.9 \\
\hline $\mathrm{R}(10,11)$ & 1.393 & 1.382 & $A(4,6,20)$ & 122.4 & 122.6 \\
\hline $\mathrm{R}(10,19)$ & 1.402 & 1.384 & $A(7,6,20)$ & 119.2 & 119.5 \\
\hline $\mathrm{R}(11,12)$ & 1.083 & 0.931 & $\mathrm{~A}(6,7,8)$ & 125.4 & 125.2 \\
\hline $\mathrm{R}(11,13)$ & 1.389 & 1.376 & $\mathrm{~A}(6,7,9)$ & 117.5 & 118.1 \\
\hline $\mathrm{R}(13,14)$ & 1.083 & 0.931 & A $(8,7,9)$ & 117.1 & 116.7 \\
\hline $\mathrm{R}(13,15)$ & 1.402 & 1.380 & $\mathrm{~A}(7,9,10)$ & 122.9 & 121.8 \\
\hline $\mathrm{R}(15,16)$ & 1.083 & 0.929 & $\mathrm{~A}(9,10,11)$ & 117.5 & 116.8 \\
\hline $\mathrm{R}(15,17)$ & 1.385 & 1.372 & A $(9,10,19)$ & 121.2 & 121.3 \\
\hline $\mathrm{R}(17,18)$ & 1.082 & 0.930 & $\mathrm{~A}(11,10,19)$ & 121.3 & 121.8 \\
\hline $\mathrm{R}(17,19)$ & 1.406 & 1.397 & $\mathrm{~A}(10,11,12)$ & 119.4 & 120.8 \\
\hline $\mathrm{R}(19,20)$ & 1.441 & 1.438 & $\mathrm{~A}(10,11,13)$ & 118.9 & 118.3 \\
\hline $\mathrm{R}(21,22)$ & 1.009 & 0.860 & $\mathrm{~A}(12,11,13)$ & 121.8 & 120.9 \\
\hline $\mathrm{R}(21,23)$ & 1.010 & 0.860 & A $(11,13,14)$ & 119.4 & 119.4 \\
\hline $\mathrm{R}(24,25)$ & 1.161 & 1.147 & $\mathrm{~A}(11,13,15)$ & 120.7 & 121.2 \\
\hline $\mathrm{R}(26,27)$ & 1.397 & 1.374 & $\mathrm{~A}(14,13,15)$ & 119.9 & 119.4 \\
\hline $\mathrm{R}(26,35)$ & 1.400 & 1.383 & A $(13,15,16)$ & 120.0 & 120.0 \\
\hline $\mathrm{R}(27,28)$ & 1.085 & 0.931 & A $(13,15,17)$ & 120.2 & 120.0 \\
\hline $\mathrm{R}(27,29)$ & 1.396 & 1.393 & A $(16,15,17)$ & 119.9 & 120.0 \\
\hline $\mathrm{R}(29,30)$ & 1.084 & 0.930 & A $(15,17,18)$ & 120.7 & 119.8 \\
\hline $\mathrm{R}(29,31)$ & 1.394 & 1.356 & A $(15,17,19)$ & 120.0 & 120.2 \\
\hline $\mathrm{R}(31,32)$ & 1.084 & 0.930 & A $(18,17,19)$ & 119.3 & 120.0 \\
\hline $\mathrm{R}(31,33)$ & 1.396 & 1.357 & A $(10,19,17)$ & 118.9 & 118.4 \\
\hline $\mathrm{R}(33,34)$ & 1.084 & 0.930 & $\mathrm{~A}(10,19,20)$ & 116.4 & 116.6 \\
\hline $\mathrm{R}(33,35)$ & 1.393 & 1.376 & $\mathrm{~A}(17,19,20)$ & 124.6 & 124.9 \\
\hline $\mathrm{R}(35,36)$ & 1.085 & 0.931 & $\mathrm{~A}(1,20,6)$ & 122.6 & 123.5 \\
\hline \multirow[t]{18}{*}{ RMSD } & & 0.074 & $\mathrm{~A}(1,20,19)$ & 114.7 & 114.0 \\
\hline & & & $\mathrm{A}(6,20,19)$ & 122.7 & 122.5 \\
\hline & & & $\mathrm{A}(2,21,22)$ & 118.7 & 120.0 \\
\hline & & & $\mathrm{A}(2,21,23)$ & 117.6 & 120.0 \\
\hline & & & $\mathrm{A}(22,21,23)$ & 116.2 & 120.0 \\
\hline & & & $\mathrm{A}(4,26,27)$ & 120.0 & 121.7 \\
\hline & & & $\mathrm{A}(4,26,35)$ & 121.2 & 120.5 \\
\hline & & & A $(27,26,35)$ & 118.8 & 117.7 \\
\hline & & & A $(26,27,28)$ & 119.6 & 119.9 \\
\hline & & & A $(26,27,29)$ & 120.7 & 120.2 \\
\hline & & & A $(28,27,29)$ & 119.7 & 120.0 \\
\hline & & & A $(27,29,30)$ & 119.8 & 119.7 \\
\hline & & & A $(27,29,31)$ & 120.1 & 120.7 \\
\hline & & & A $(30,29,31)$ & 120.2 & 119.6 \\
\hline & & & A $(29,31,32)$ & 120.2 & 120.0 \\
\hline & & & A $(29,31,33)$ & 119.6 & 120.0 \\
\hline & & & $\mathrm{A}(32,31,33)$ & 120.2 & 120.0 \\
\hline & & & A $(31,33,34)$ & 120.1 & 120.1 \\
\hline
\end{tabular}

TABle 1: Continued.

\begin{tabular}{|c|c|c|c|c|c|}
\hline Bond length $(\AA)$ & B3LYP & $\operatorname{Exp}^{a}$ & Bond angle $\left({ }^{\circ}\right)$ & B3LYP & $\operatorname{Exp}^{a}$ \\
\hline & & & A $(31,33,35)$ & 120.2 & 119.7 \\
\hline & & & $\mathrm{A}(34,33,35)$ & 119.7 & 120.2 \\
\hline & & & A $(26,35,33)$ & 120.6 & 121.7 \\
\hline & & & $A(26,35,36)$ & 120.1 & 119.1 \\
\hline & & & A $(33,35,36)$ & 119.2 & 119.2 \\
\hline RMSD & & & & & 0.9 \\
\hline
\end{tabular}

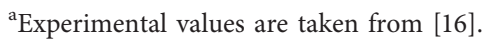

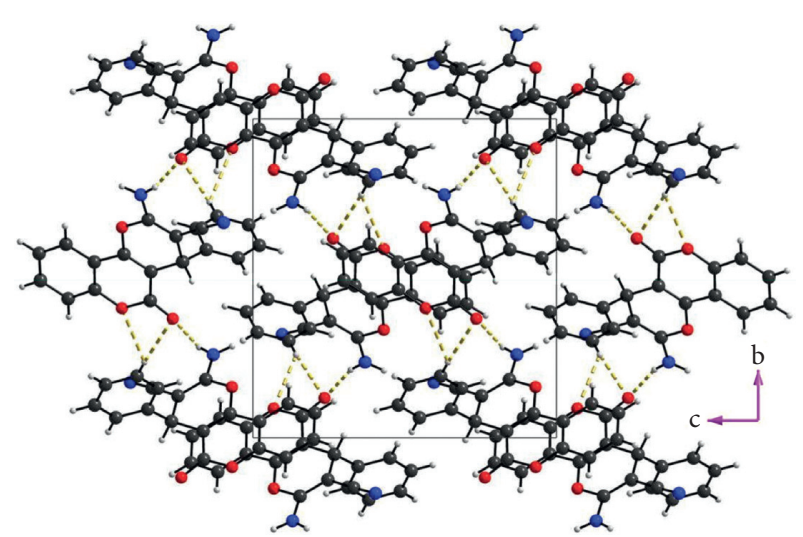

Figure 3: Projection view of the crystalline structure of Chrom-D along the " $a$ "-axis showing the intermolecular hydrogen bonds with dashed lines.

highest negative charges were occupied by oxygen atom $\mathrm{O} 8$ and nitrogen atom N25. It confirms the presence of a system of $\mathrm{N}-\mathrm{H} \cdots \mathrm{O}, \mathrm{C}-\mathrm{H} \cdots \mathrm{O}$, and $\mathrm{N}-\mathrm{H} \cdots \mathrm{N}$ H-bonding.

Fukui functions are extensively used in the conceptual density functional theory to identify the reactive sites [25-29]. These parameters examine the tendency of a molecule to lose or gain an electron, thus predicting which atom in the molecule would be more prone to a nucleophilic or electrophilic attack. The Fukui function $f_{j}^{+}$, referring to a gain of an electron, is commonly called the index of nucleophilic attack. Despite, the loss of an electron is designed by the Fukui function $f_{j}^{-}$which is also termed the index of electrophilic attack.

The condensed atomic Fukui functions for electrophilic $f_{j}^{-}$, nucleophilic $f_{j}^{+}$, and radical $f_{j}^{\circ}$ attacks on the $j^{\text {th }}$ atom site are defined as

$$
\begin{aligned}
& f_{j}^{-}=q_{j}(N)-q_{j}(N-1), \\
& f_{j}^{+}=q_{j}(N+1)-q_{j}(N), \\
& f_{j}^{\circ}=\frac{1}{2}\left[q_{j}(N+1)-q_{j}(N-1)\right],
\end{aligned}
$$

where $q_{j}$ is the atomic charge (Mulliken, Hirshfeld, or $\mathrm{NBO})$ at the $j^{\text {th }}$ atomic site and $(N),(N-1)$, and $(N+1)$ are the total electrons present in the neutral, cation, and anion state of the studied molecule, respectively.

The condensed dual descriptor $\Delta f(r)$ is defined as $\Delta f(r)=f_{j}^{+}-f_{j}^{-}$. The condensed Fukui functions and dual descriptor, calculated based on the NBO charge distribution, are listed in Table S2. 

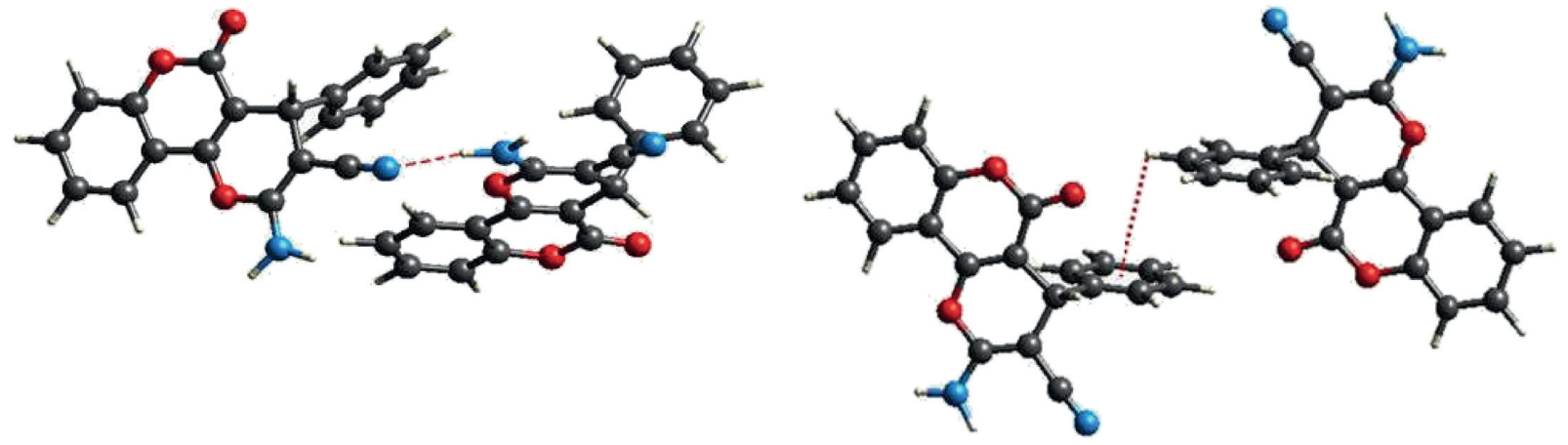

(a)

(b)

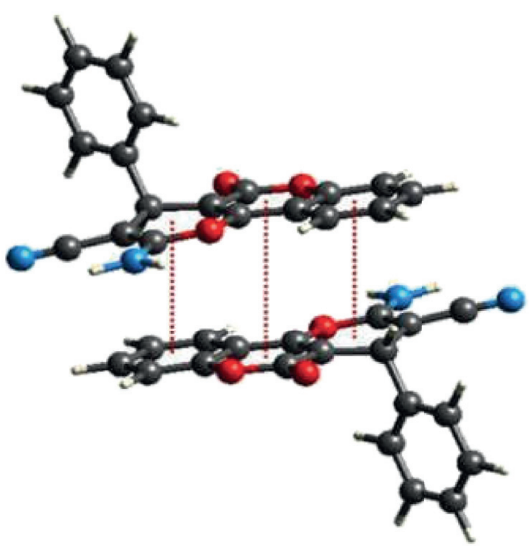

(c)

Figure 4: Selected views highlighting individual (a) N-H. .N, (b) C-H. . $\pi$, and (c) $\pi \ldots \pi$ intermolecular interactions indicated in dashed lines.

Negative values of Fukui functions indicate that an addition of one electron to the molecule reduces its electron density. Instead, excluding an electron leads to an increase in the electron density. Negative values of $\Delta f(r)$ indicate that the corresponding atoms are prone to the electrophilic attack, whereas positive values reveal that the corresponding atoms are prone to the nucleophilic attack. In the case of our investigated compound, the order of the reactivity was classified as $\mathrm{N} 21>\mathrm{O} 8>\mathrm{N} 25>\mathrm{C} 3>\mathrm{O} 1>\mathrm{O} 9$ for "nucleophilic atoms" and as $\mathrm{C} 7>\mathrm{C} 2>\mathrm{H} 22>\mathrm{H} 23>\mathrm{C} 24$ for electrophilic atoms.

2.6. Vibrational Analysis. The infrared spectrum of the Chrom-D compound is recorded in the range between 400 and $4000 \mathrm{~cm}^{-1}$ and plotted with the calculated one in Figure 8 . The observed and calculated wavenumbers as well as the probable assignments of fundamental vibrational modes are given in Table 2.

Applying a scale factor $[30,31]$ is a moderator to overcome the misleading between experimental and computed values. The title molecule is formed by 36 atoms which undergo with 102 normal vibrational modes. The optimized structure deals with the $\mathrm{C}_{1}$ point group symmetry. Theoretical and experimental IR spectra analysis of Chrom-D has been made based on the main characteristic of $\mathrm{N}-\mathrm{H}, \mathrm{C} \equiv \mathrm{N}$, $\mathrm{C}-\mathrm{H}$, and $\mathrm{C}=\mathrm{O}$ vibrations.
The stretching modes of the $\mathrm{NH}_{2}$ amino group are generally appeared in the region of 3500-3380 and $3400-3250 \mathrm{~cm}^{-1}$, for symmetric and asymmetric vibrations, respectively [32]. In the current work, the asymmetric and symmetric $\mathrm{NH}_{2}$ vibrations are observed at 3377 and $3305 \mathrm{~cm}^{-1}$, respectively. Their corresponding calculated wavenumbers are 3533 and $3427 \mathrm{~cm}^{-1}$. This vibration mode is considered as a pure mode regarding to its TED contribution (99\%). The broadening of the bands reveals a strong hydrogen-bonding interaction between the adjacent molecules through their $\mathrm{N}-\mathrm{H}$ groups. The literature reveals that the stretching vibrations of the triply bonded groups were expected to be in the range of $2500-2000 \mathrm{~cm}^{-1}$ [33]. Herein, the $\mathrm{C} \equiv \mathrm{N}$ stretching vibration is observed at $2199 \mathrm{~cm}^{-1}$ in the infrared spectrum. Its calculated frequency is found to be at $2180 \mathrm{~cm}^{-1}$. This vibration may be affected by the hydrogen bonding between $\mathrm{C} \equiv \mathrm{N}$ and $\mathrm{NH}_{2}$ in the crystal lattice.

Generally, the $\mathrm{C}-\mathrm{H}$ stretching vibrations are found between 3100 and $3000 \mathrm{~cm}^{-1}$. In our case, C-H stretching vibrations are observed between 3093 and $3000 \mathrm{~cm}^{-1}$. For the $\mathrm{C}=\mathrm{O}$ stretching, a broad band located at $1660 \mathrm{~cm}^{-1}$ in the theoretical spectrum can be accredited to this stretching. Experimentally, this band was observed at $1715 \mathrm{~cm}^{-1}$. Besides, another strong band appeared, theoretically, at $1656 \mathrm{~cm}^{-1}$ (64\%) which may be assigned to $\mathrm{C}=\mathrm{C}$ stretching vibrations. All these results with the appropriate TED percentage and assignments are given in Table 2. 

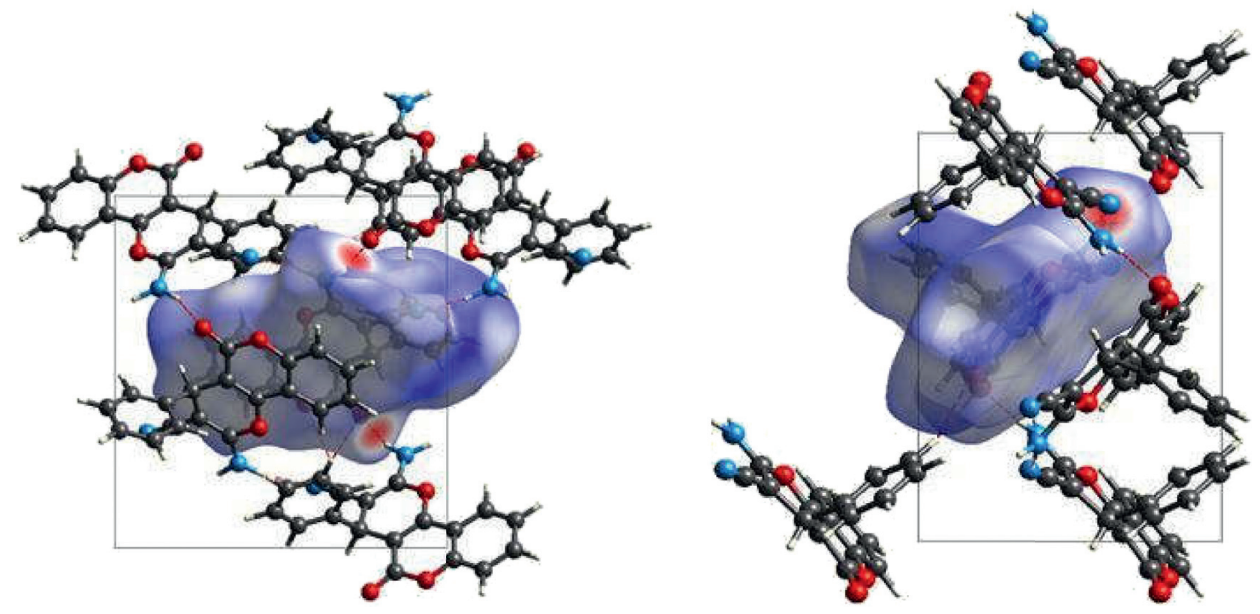

(a)
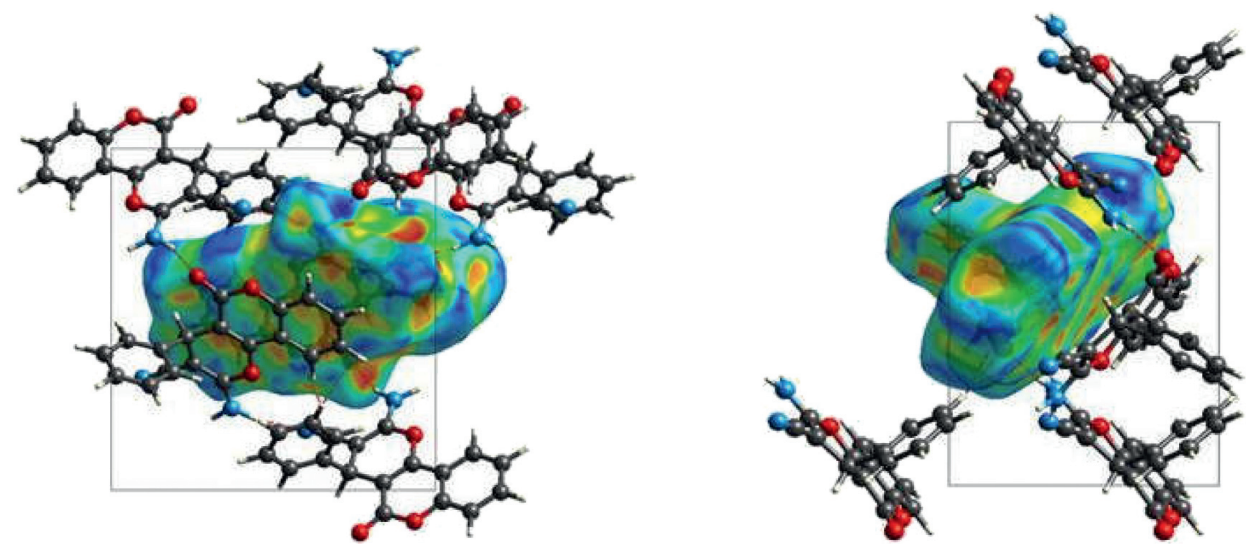

(b)

FIgURe 5: Graphical plots of Hirshfeld surfaces of Chrom-D mapped with (a) $d_{\text {norm }}$ and (b) shape index along with the " $a$ "-axis (left) and " $c$ "axis (right).

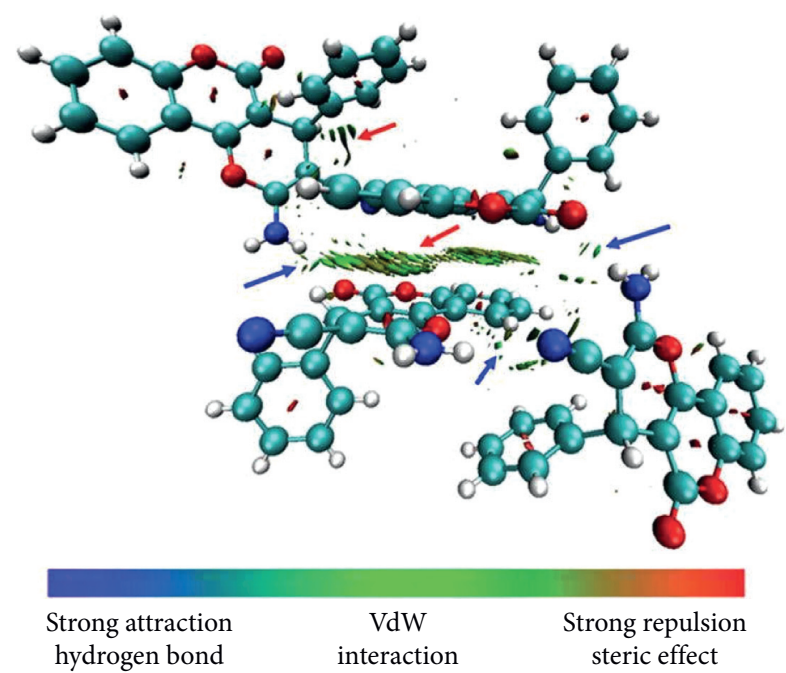

FIgURe 6: RDG analysis of the Chrom-D compound.

The correlation between the scaled and experimental frequencies is plotted in Figure 9. From the graph, a linearity was found between the scaled and the observed frequencies.
The correlation coefficient $\left(R^{2}\right)$ is found to be 0.99925 . Thus, it may be concluded that the calculated frequencies are consistent with the experimental ones.

2.7. NMR Spectral Analysis. NMR spectroscopy is one of the most important techniques used for the structural analysis of organic molecules [34]. ${ }^{1} \mathrm{H}-\mathrm{NMR}$ spectrum gives information about the number of different protons and the nature of their chemical environment. The ${ }^{13} \mathrm{C}-\mathrm{NMR}$ spectrum provides the structural information about carbon atoms. Starting from the optimized structure, ${ }^{1} \mathrm{H}-\mathrm{NMR}$ and ${ }^{13} \mathrm{C}$ NMR were calculated, in the gas phase, using the gaugeincluding atomic orbitals (GIAO). The predicted ${ }^{1} \mathrm{H}-\mathrm{NMR}$ and ${ }^{13} \mathrm{C}$-NMR isotropic chemical shifts with respect to the TMS B3LYP/6-311+G(2d, p) GIAO reference are listed and compared with the experimental data in Table 3.

Experimental ${ }^{1} \mathrm{H}-\mathrm{NMR}$ and ${ }^{13} \mathrm{C}-\mathrm{NMR}$ spectra recorded in DMSO- $d_{6}$ are illustrated in Figure 10.

Accordingly, all ${ }^{1} \mathrm{H}-\mathrm{NMR}$ chemical shifts are localized in the range between 7.914 and $7.249 \mathrm{ppm}$, except H4 (H5 in Table 3), wherein its chemical shift was $4.449 \mathrm{ppm}$. These results are similar to those obtained by Sharma et al. [16]. 


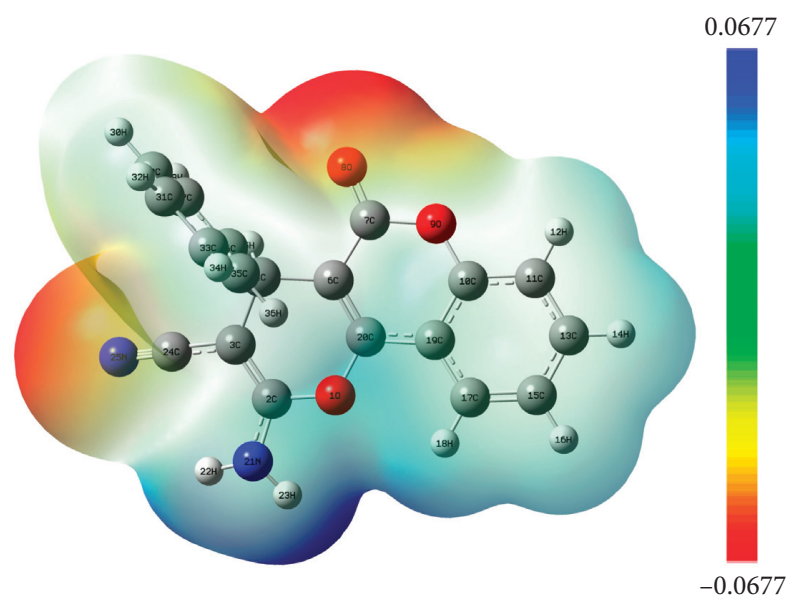

Figure 7: The MEP surface graph of Chrom-D.

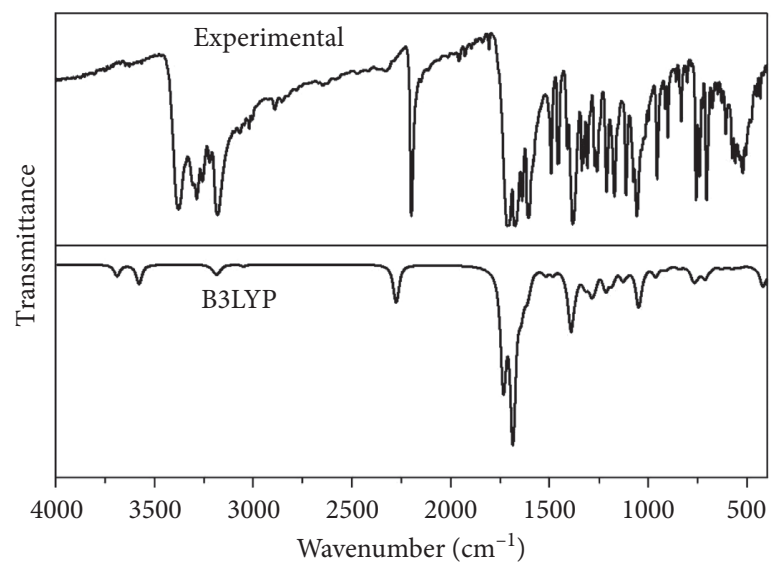

Figure 8: Experimental and theoretical FT-IR spectra of Chrom-D.

TABLE 2: Experimental and calculated frequencies $\left(\mathrm{cm}^{-1}\right)$ using B3LYP/6-311++G(d, p) along with the vibrational assignments based on the percentage of the total energy distribution (TED).

\begin{tabular}{|c|c|c|c|c|c|c|}
\hline \multirow{2}{*}{ No. } & \multicolumn{2}{|c|}{ Experimental } & \multicolumn{2}{|c|}{ Calculated } & \multirow{2}{*}{$\operatorname{IR}^{\mathrm{int}}$} & \multirow{2}{*}{ Assignments (\% TED) } \\
\hline & $v_{\exp }{ }^{a}$ & $v_{\exp }^{\mathrm{b}}$ & $v_{\text {harmonic }}$ & $v_{\text {scaled }}^{c}$ & & \\
\hline 1 & 3377 & 3379 & 3688 & 3533 & 105.74 & vNH (99) \\
\hline 2 & 3305 & & 3577 & 3427 & 175.24 & $v \mathrm{NH}(99)$ \\
\hline- & 3285 & & - & - & - & - \\
\hline- & 3254 & 3259 & - & - & - & - \\
\hline- & 3219 & & - & - & - & - \\
\hline- & 3180 & 3178 & - & - & - & - \\
\hline 3 & 3093 & & 3213 & 3078 & 7.1 & $\nu \mathrm{CH}(86)$ \\
\hline 4 & & & 3206 & 3072 & 4.75 & $\nu \mathrm{CH}(88)$ \\
\hline 5 & 3063 & & 3196 & 3062 & 10.45 & $\nu \mathrm{CH}(88)$ \\
\hline 6 & & & 3191 & 3057 & 23.67 & $\nu \mathrm{CH}(95)$ \\
\hline 7 & & & 3184 & 3050 & 2.47 & $\nu \mathrm{CH}(86)$ \\
\hline 8 & 3042 & & 3180 & 3047 & 47.3 & vCH (99) \\
\hline 9 & & & 3173 & 3039 & 9.97 & $\nu \mathrm{CH}(96)$ \\
\hline 10 & 3030 & & 3164 & 3031 & 3.71 & $\nu \mathrm{CH}(98)$ \\
\hline 11 & 3019 & & 3161 & 3028 & 7.33 & $\nu \mathrm{CH}(97)$ \\
\hline- & 3001 & - & - & - & - & - \\
\hline- & 2889 & - & - & - & - & - \\
\hline 12 & 2851 & 2878 & 3047 & 2919 & 14.06 & $\nu \mathrm{CH}(100)$ \\
\hline 13 & 2199 & 2199 & 2276 & 2180 & 342.09 & $\nu \mathrm{NC}(94)$ \\
\hline
\end{tabular}


TABle 2: Continued.

\begin{tabular}{|c|c|c|c|c|c|c|}
\hline \multirow{2}{*}{ No. } & \multicolumn{2}{|c|}{ Experimental } & \multicolumn{2}{|c|}{ Calculated } & \multirow{2}{*}{$I^{\text {int }}$} & \multirow{2}{*}{ Assignments (\% TED) ${ }^{\mathrm{d}}$} \\
\hline & $v_{\exp }^{\mathrm{a}}$ & $v_{\exp }^{\mathrm{b}}$ & $v_{\text {harmonic }}$ & $v_{\text {scaled }}{ }^{\mathrm{c}}$ & & \\
\hline 14 & 1715 & 1695 & 1733 & 1660 & 998.02 & $\nu \mathrm{OC}(82)$ \\
\hline 15 & 1678 & & 1685 & 1656 & 1462.28 & $\nu \mathrm{CC}(64)$ \\
\hline 16 & 1637 & & 1648 & 1620 & 42.41 & $\nu \mathrm{CC}(43) \beta \mathrm{HNH}(25)$ \\
\hline 17 & 1605 & 1603 & 1642 & 1614 & 237.72 & $\nu \mathrm{CC}(65) \beta \mathrm{HCC}(12)$ \\
\hline 18 & & & 1636 & 1608 & 3.88 & $\nu \mathrm{CC}(58) \beta \mathrm{HCC}(22)$ \\
\hline 19 & 1587 & 1587 & 1621 & 1594 & 0.56 & $\nu \mathrm{CC}(66)$ \\
\hline 20 & 1578 & & 1612 & 1585 & 177.78 & $\nu \mathrm{CC}(19) \beta \mathrm{HNH}(56)$ \\
\hline 21 & & & 1601 & 1573 & 42.88 & $v \mathrm{CC}(56)$ \\
\hline 22 & 1491 & 1479 & 1522 & 1496 & 13.41 & $\beta \mathrm{HCC}(63) \nu \mathrm{CC}(12)$ \\
\hline 23 & & & 1517 & 1491 & 41.7 & $\beta \mathrm{HCC}(44)$ \\
\hline 24 & 1452 & & 1482 & 1457 & 16.89 & $\nu \mathrm{CC}(27) \beta \mathrm{HCC}(62)$ \\
\hline 25 & 1408 & & 1481 & 1456 & 40.65 & $\beta \mathrm{HCC}(44)$ \\
\hline 26 & 1383 & 1389 & 1420 & 1396 & 38.81 & $v \mathrm{NC}(34)$ \\
\hline 27 & & & 1391 & 1367 & 515.9 & $\nu \mathrm{CC}(16) \tau \mathrm{HCCC}(29)$ \\
\hline 28 & & & 1373 & 1350 & 74.44 & $\beta \mathrm{HCC}(78)$ \\
\hline 29 & 1336 & & 1360 & 1336 & 45.6 & $\nu \mathrm{CC}(82)$ \\
\hline 30 & 1329 & & 1345 & 1322 & 7.88 & $\nu \mathrm{CC}(54) \beta \mathrm{HCC}(29)$ \\
\hline 31 & 1308 & & 1319 & 1297 & 138.06 & $\nu \mathrm{CC}(16) \beta \mathrm{HCC}(29)$ \\
\hline 32 & 1274 & & 1289 & 1267 & 169.56 & $\nu \mathrm{CC}(12) \beta \mathrm{HCC}(12) \beta \mathrm{HCC}(10) \tau \mathrm{HCCC}(15)$ \\
\hline 33 & 1258 & & 1276 & 1255 & 29.73 & $\nu \mathrm{CC}(22) \beta \mathrm{HCC}(44)$ \\
\hline 34 & & & 1270 & 1248 & 94.62 & $\nu \mathrm{OC}(37) \tau \mathrm{HCCC}(12)$ \\
\hline 35 & 1211 & & 1220 & 1200 & 60.38 & $\nu \mathrm{CH}(28) \beta \mathrm{HNC}(19)$ \\
\hline 36 & & & 1215 & 1194 & 127.13 & $\nu \mathrm{CC}(23) \nu \mathrm{CC}(29)$ \\
\hline 37 & & & 1201 & 1180 & 1.11 & $\nu \mathrm{CC}(17) \beta \mathrm{HCC}(73)$ \\
\hline 38 & 1173 & 1173 & 1195 & 1174 & 8.66 & $\nu \mathrm{CC}(56)$ \\
\hline 39 & & & 1187 & 1166 & 57.88 & $\nu \mathrm{CC}(18) \beta \mathrm{HCC}(15)$ \\
\hline 40 & & & 1181 & 1161 & 67.71 & $\nu \mathrm{CC}(11) \nu \mathrm{OC}(32 \beta \mathrm{HCC}(19$ \\
\hline 41 & & & 1177 & 1157 & 0.43 & $\nu \mathrm{CC}(12) \beta \mathrm{HCC}(78)$ \\
\hline 42 & & & 1170 & 1150 & 4.98 & $\beta \operatorname{HCC}(55)$ \\
\hline 43 & 1113 & & 1129 & 1109 & 106.54 & $\nu \mathrm{OC}(10) \beta \mathrm{HCC}(32) \beta \mathrm{CCC}(25)$ \\
\hline 44 & 1076 & & 1103 & 1085 & 27.76 & $\nu \mathrm{CC}(57) \beta \mathrm{HCC}(29)$ \\
\hline 45 & 1058 & 1051 & 1054 & 1036 & 19.48 & $\nu \mathrm{CC}(43) \beta \mathrm{HCC}(15)$ \\
\hline 46 & & & 1051 & 1033 & 250.8 & $\nu \mathrm{OC}(57)$ \\
\hline 47 & & & 1044 & 1026 & 108.84 & $\nu \mathrm{CC}(32) \beta \mathrm{HCC}(12) \beta \mathrm{CCC}(24)$ \\
\hline 48 & 1000 & & 1020 & 1002 & 9.28 & $\nu \mathrm{OC}(42) \beta \mathrm{HNC}(16)$ \\
\hline 49 & & & 1015 & 998 & 5.57 & $\nu \mathrm{CC}(23) \beta \mathrm{CCC}(59)$ \\
\hline 50 & & & 1009 & 992 & 0.2 & $\tau \mathrm{HCCH}(90)$ \\
\hline 51 & & & 1006 & 989 & 0.05 & $\tau \mathrm{HCCH}(96)$ \\
\hline 52 & & & 990 & 973 & 0.11 & $\tau \mathrm{HCCC}(93)$ \\
\hline 53 & 954 & & 975 & 959 & 2.83 & $\tau \mathrm{HCCC}(95)$ \\
\hline 54 & & & 963 & 946 & 87.65 & vOC (45) \\
\hline 55 & 916 & 924 & 936 & 920 & 6.94 & $\tau \operatorname{HCCC}(72)$ \\
\hline 56 & 899 & & 911 & 896 & 33.7 & $\nu \mathrm{CC}(10) \beta \mathrm{CCC}(37)$ \\
\hline 57 & 859 & & 879 & 864 & 1.55 & $\tau \operatorname{HCCC}(84)$ \\
\hline 58 & & & 855 & 840 & 0.02 & $\tau \mathrm{HCCC}(98)$ \\
\hline 59 & 831 & 837 & 843 & 828 & 22.38 & $\beta \mathrm{CCC}(25) \nu \mathrm{CC}(35)$ \\
\hline 60 & 804 & & 813 & 800 & 3.79 & $\beta \mathrm{CCC}(13) \tau \mathrm{HCCC}(10)$ \\
\hline 61 & & & 791 & 777 & 2.77 & $\tau \mathrm{HCCC}(11) \gamma \mathrm{OCCC}(26)$ \\
\hline 62 & 756 & & 771 & 758 & 116.29 & $\tau \operatorname{HCCC}(69)$ \\
\hline 63 & & & 755 & 742 & 31.51 & $\tau \mathrm{CCCC}(11)(16) \gamma \mathrm{OCCC}(17)$ \\
\hline 64 & 739 & 732 & 748 & 735 & 35.64 & $\tau$ CCCC (11) $\tau$ OCOC (13) \\
\hline 65 & & & 732 & 719 & 4.77 & $\tau$ OCOC $(40)$ \\
\hline 66 & 705 & & 715 & 702 & 67.54 & $\beta \mathrm{CCC}(23) \tau \mathrm{HCCC}(24)$ \\
\hline 67 & & & 709 & 697 & 40.64 & $\tau \operatorname{HCCC~(53)~} \tau \operatorname{CCCC~(26)~}$ \\
\hline 68 & 674 & & 691 & 679 & 5.41 & $\beta \operatorname{CCO}(34)$ \\
\hline 69 & & & 681 & 670 & 18.9 & $\beta \operatorname{CCC}(26)$ \\
\hline 70 & 647 & & 661 & 650 & 1.01 & $\gamma \operatorname{OCCC~(13)~} \gamma \operatorname{CCCC}(32)$ \\
\hline 71 & 630 & & 634 & 623 & 10.07 & $\beta \operatorname{OCO}(69)$ \\
\hline 72 & & & 628 & 617 & 3.89 & $\beta \operatorname{CCC~(61)~}$ \\
\hline
\end{tabular}


TABLE 2: Continued.

\begin{tabular}{|c|c|c|c|c|c|c|}
\hline \multirow{2}{*}{ No. } & \multicolumn{2}{|c|}{ Experimental } & \multicolumn{2}{|c|}{ Calculated } & \multirow{2}{*}{$I^{\text {int }}$} & \multirow{2}{*}{ Assignments (\% TED $)^{\mathrm{d}}$} \\
\hline & $v_{\exp }{ }^{\mathrm{a}}$ & $v_{\exp }^{\mathrm{b}}$ & $v_{\text {harmonic }}$ & $v_{\text {scaled }}{ }^{\mathrm{c}}$ & & \\
\hline 73 & 607 & 617 & 622 & 611 & 13.24 & $\beta \operatorname{CCC~(55)~}$ \\
\hline 74 & 578 & & 588 & 578 & 12.01 & $\beta \operatorname{CCC}(55)$ \\
\hline 75 & 559 & & 572 & 562 & 18.07 & $\tau \mathrm{NCCC}(19) \tau \mathrm{NCCC}(14)$ \\
\hline 76 & 535 & & 547 & 538 & 9.44 & $\tau \operatorname{NCCC}(16)$ \\
\hline 77 & 520 & & 535 & 526 & 6.72 & $\tau \mathrm{NCCC}(10) \tau \mathrm{CCCC}(52)$ \\
\hline 78 & 504 & & 521 & 512 & 4.16 & $\beta \mathrm{CCN}(18) \tau \mathrm{CCCC}(18)$ \\
\hline 79 & 480 & & 483 & 474 & 2.92 & $\nu$ CC (11) $\beta$ CCC (16) \\
\hline 80 & 451 & & 458 & 450 & 6.98 & $\beta \operatorname{CCC}(16)$ \\
\hline 81 & 433 & & 445 & 438 & 3.07 & $\tau \operatorname{CCCC~}(40) \tau \operatorname{CCCC~(19)~}$ \\
\hline 82 & 416 & & 421 & 414 & 167.42 & $\tau \mathrm{HNCC}(89)$ \\
\hline 83 & & & 412 & 405 & 0.34 & $\tau \operatorname{CCCC~}(92)$ \\
\hline 84 & & & 386 & 380 & 49.63 & $\beta \mathrm{CCC}(32) \tau \mathrm{HNCC}(15)$ \\
\hline 85 & & & 363 & 357 & 223.41 & $\tau \mathrm{HNCC}(62)$ \\
\hline 86 & & & 353 & 347 & 6.7 & $\beta \operatorname{CCC}(32)$ \\
\hline 87 & & & 343 & 337 & 39.01 & $\beta \operatorname{CCC~(14)~} \beta \operatorname{CCC}(11) \tau \operatorname{HNCC}(10)$ \\
\hline 88 & & & 300 & 295 & 24.04 & $\nu \mathrm{CC}(10) \tau \mathrm{CCCC}(19)$ \\
\hline 89 & & & 286 & 281 & 4.64 & $\beta \operatorname{CCC~(22)~} \tau$ CCCC (19) s97 (11) \\
\hline 90 & & & 277 & 273 & 1.43 & $\beta \operatorname{CCC~}(22) \tau \operatorname{CCCC~}(25$ \\
\hline 91 & & & 248 & 244 & 0.04 & $\beta \operatorname{CCC}(53)$ \\
\hline 92 & & & 211 & 207 & 3.43 & $\tau \operatorname{CCCC~(11)~} \gamma \operatorname{CCCC~(39)~}$ \\
\hline 93 & & & 196 & 193 & 6.83 & $\tau \operatorname{CCOC}(22) \tau \operatorname{CCCC}(10)$ \\
\hline 94 & & & 178 & 175 & 7.22 & $\beta \operatorname{CCO}(29) \gamma \operatorname{CCCC~(11)~}$ \\
\hline 95 & & & 130 & 127 & 4.63 & $\beta \operatorname{CCC}(10) \tau \operatorname{COCC}(43)$ \\
\hline 96 & & & 112 & 110 & 7.73 & $\beta \mathrm{CCN}(51)$ \\
\hline 97 & & & 99 & 97 & 1.56 & $\tau \operatorname{COCC}(66)$ \\
\hline 98 & & & 84 & 83 & 3.44 & $\tau \operatorname{CCCC~}(63)$ \\
\hline 99 & & & 59 & 58 & 0.88 & $\beta \mathrm{CCN}(10) \gamma \mathrm{CCCC}(52)$ \\
\hline 100 & & & 38 & 38 & 0.62 & $\tau$ COCC $(59)$ \\
\hline 101 & & & 32 & 31 & 1.65 & $\tau$ CCCC $(10) \tau$ CCCC $(68)$ \\
\hline 102 & & & 26 & 26 & 6.55 & $\tau \operatorname{CCCC~}(58)$ \\
\hline
\end{tabular}

$\mathrm{IR}^{\text {int }}$ : infrared intensity (in $\mathrm{km} / \mathrm{mol}$ ); $\nu$ : stretching; $\beta$ : in-plane bending; $\gamma$ : out-of-plane bending; $\tau$ : torsion; TED: total energy distribution. ${ }^{a}$ This work. ${ }^{\mathrm{b}} \mathrm{Values}$ taken from [16]. ${ }^{\circ}$ The harmonic frequencies are scaled by 0.958 in the range of wavenumbers above $1700 \mathrm{~cm}^{-1}$ and 0.983 below $1700 \mathrm{~cm}^{-1}$. ${ }^{\mathrm{d}}$ TED more than $10 \%$.

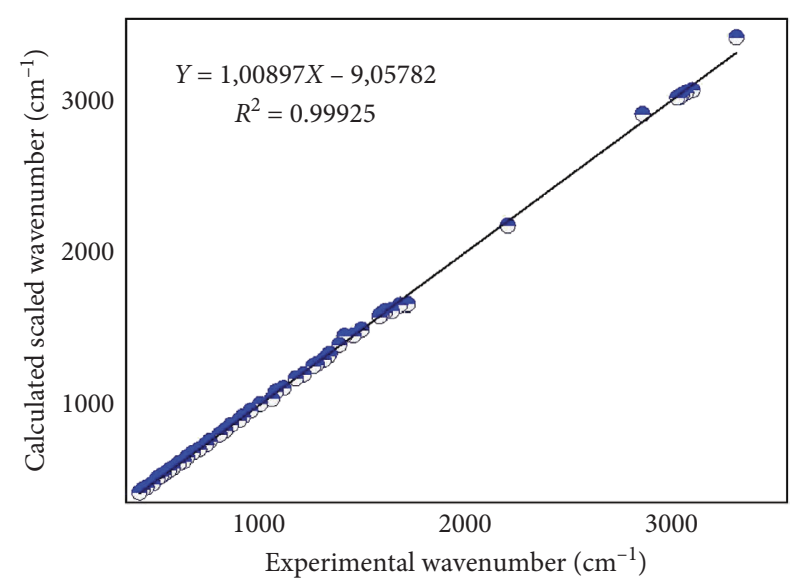

FIgURE 9: The linear regression between the calculated (scaled) and experimental frequencies of Chrom-D.

The calculated values of the ${ }^{1} \mathrm{H}-\mathrm{NMR}$ chemical shift are in good agreement with the experimental data, except for the hydrogen atoms of the $\mathrm{NH}_{2}$ group. These deviations may be due to the intermolecular $\mathrm{H}$-bonding between the $\mathrm{NH}_{2}$ group and the neighboring molecules. It is well known in the literature that $\mathrm{H}$-bond interactions may lead to a large ${ }^{1} \mathrm{H}$ NMR chemical shift $[35,36]$. Concerning the ${ }^{13} \mathrm{C}-\mathrm{NMR}$ chemical shifts, results show that B3LYP/6-311++G(d,p) has slightly overestimated the experimental values. Herein, experimentally, the ${ }^{13} \mathrm{C}-\mathrm{NMR}$ chemical shifts are found approximately in the range of $37-160 \mathrm{ppm}$, whereas theoretically, the values are varied closely between 43 and $163 \mathrm{ppm}$.

2.8. Electronic Properties. TD-DFT calculations have been performed at the same level of theory to predict the absorption spectrum, excitation energies, absorption wavelengths, and oscillator strengths along with the electronic transitions and their contributions. The calculations were made in DMSO solvent within the IEFPCM solvation model. Experimental and calculated UV-vis spectra are depicted in Figure 11. Absorption wavelengths $(\lambda)$, oscillator strengths $(f)$, and excitation energies $(E)$ along with major contributions of the transitions are listed in Table 4.

As we can notice, the absorption takes place approximately between 200 and $400 \mathrm{~nm}$. Three intense electronic transitions are predicted closely at 224, 246, and $306 \mathrm{~nm}$. As 
TABLE 3: Calculated ${ }^{1} \mathrm{H}-\mathrm{NMR}$ and ${ }^{13} \mathrm{C}-\mathrm{NMR}$ chemical shifts $(\delta(\mathrm{ppm}))$ based on the TMS B3LYP/6 311+G(2d,p) GIAO reference compared with the experimental results.

\begin{tabular}{|c|c|c|c|c|c|}
\hline${ }^{1} \mathrm{H}$ & B3LYP & $\operatorname{Exp}^{a}$ & ${ }^{13} \mathrm{C}$ & B3LYP & $\operatorname{Exp}^{a}$ \\
\hline H18 & 7.95 & 7.90 & $\mathrm{C} 7$ & 163.41 & 159.96 \\
\hline $\mathrm{H} 28$ & 7.70 & 7.69 & $\mathrm{C} 2$ & 161.78 & 158.39 \\
\hline H14 & 7.66 & 7.47 & $\mathrm{C} 10$ & 161.35 & 153.82 \\
\hline H12 & 7.46 & 7.47 & C20 & 158.51 & 152.53 \\
\hline H30 & 7.45 & 7.31 & C26 & 150.82 & 143.74 \\
\hline H16 & 7.39 & 7.31 & C13 & 137.15 & 133.33 \\
\hline H32 & 7.37 & 7.27 & C27 & 136.21 & 128.94 \\
\hline H34 & 7.36 & 7.27 & C29 & 133.74 & 128.94 \\
\hline H36 & 7.14 & 7.27 & C33 & 133.57 & 128.04 \\
\hline $\mathrm{H} 22$ & 4.38 & 7.43 & C31 & 132.54 & 128.04 \\
\hline H5 & 4.28 & 4.45 & C35 & 131.87 & 127.54 \\
\hline \multirow[t]{8}{*}{$\mathrm{H} 23$} & 3.79 & 7.43 & C15 & 127.83 & 125.08 \\
\hline & & & C17 & 126.15 & 122.89 \\
\hline & & & C11 & 121.73 & 119.67 \\
\hline & & & C24 & 120.62 & 116.96 \\
\hline & & & C19 & 118.08 & 113.35 \\
\hline & & & C6 & 110.77 & 104.39 \\
\hline & & & C3 & 68.47 & 58.38 \\
\hline & & & $\mathrm{C} 4$ & 43.19 & 37.37 \\
\hline
\end{tabular}

${ }^{\mathrm{a}}$ Values are taken from [16].

shown in Table 4, the highest oscillator strength is calculated at $307 \mathrm{~nm}(f=0.301)$. Furthermore, the investigated molecule has benefits of remarkable transparency and low absorbance as shown experimentally. This behavior is considered as a good indication for the NLO applications. HOMO and LUMO frontier orbitals are extracted and plotted in Figure 12.

Obviously, the HOMO orbitals, lying at $-6.49 \mathrm{eV}$, are localized mainly on the amino, carbonitrile, and phenyl groups. Despite, the LUMO orbitals, lying at $-2.36 \mathrm{eV}$, cover the whole molecule except the phenyl group. As discussed in several previous works, the HOMO-LUMO gap energy characterizes the chemical reactivity and kinetic stability of a studied compound [37-40]. Thus, a molecule with small gap energy is more polarizable, generally, shows a high chemical reactivity and low kinetic stability, and is qualified as a soft molecule. Here, the HOMO-LUMO gap energy is calculated to be $4.13 \mathrm{eV}$. This relatively low value makes the molecule more reactive. Based on the HOMO and LUMO energy values given in Table 5, the global chemical reactivity descriptors such as hardness $(\eta)$, chemical potential $(\mu)$, softness $(S)$, electronegativity $(\chi)$, and electrophilicity index $(\omega)$ have been calculated using the following equations: $\eta=(\mathrm{IP}-\mathrm{EA}) / 2, \mu=-(\mathrm{IP}+\mathrm{EA}) / 2, S=1 / 2 \eta, \chi=(\mathrm{IP}+\mathrm{EA}) / 2$, and $\omega=\mu^{2} / 2 \eta$, where IP and EA are the ionization potential and electron affinity, respectively.

The electron affinity is the amount of energy spent to the neutral molecule to gain precisely one electron from a donor. IP and EA can be expressed through HOMO and LUMO energies as $\mathrm{IP}=-E_{\mathrm{HOMO}}$ and $\mathrm{EA}=-E_{\mathrm{LUMO}}$. Accordingly, the ionization potential and the electron affinity of the title compound are 6.49 and $2.36 \mathrm{eV}$, respectively. The calculated values of the global hardness, global softness, chemical potential, and global electrophilicity index are 2.06, 0.24, -4.43 , and $4.75 \mathrm{eV}$, respectively. Its low value of the chemical potential and high value of the global electrophilicity index point to a considerable electrophilic character of the molecule. In addition, the dipole moment calculated in DMSO solvent is found to be $11 \mathrm{D}$. This value supports the presence of several intermolecular interactions and confirms the tautomeric effect within the crystal lattice.

2.9. Nonlinear Optical Properties. In the current research field, NLO is the most useful concept to evaluate optoelectronic properties of a molecular system [41]. In order to get insight about the nonlinear optical properties of the studied compound, the dipole moment, polarizabilities, and first-order hyperpolarizabilities have been calculated in the gas phase and in DMSO solvent.

The total dipole moment and first-order hyperpolarizability of Chrom-D are found to be $11 \mathrm{D}$ and $5.02 \times 10^{-30} \mathrm{esu}$, respectively. Based on these findings, Chrom-D has a total dipole moment of 8 times greater than that of urea (5.5 times in the gas phase). Besides, the firstorder hyperpolarizability is almost 13 times greater than that of urea ( $\mu$ and $\beta$ of urea are $1.3732 \mathrm{D}$ and $\left.0.3728 \times 10^{-30} \mathrm{esu}\right)$.

The high value of first-order hyperpolarizability explains the intramolecular charge transfer within the molecule. Therefore, the highest value of the $\beta_{Y Y Y}$-component of the first-order hyperpolarizability points to a charge delocalization along the "YYY" direction. This charge delocalization has been proved by the low gap energy $(4.13 \mathrm{eV})$. The above results allow us to conclude that Chrom-D is an outstanding material for NLO applications. 

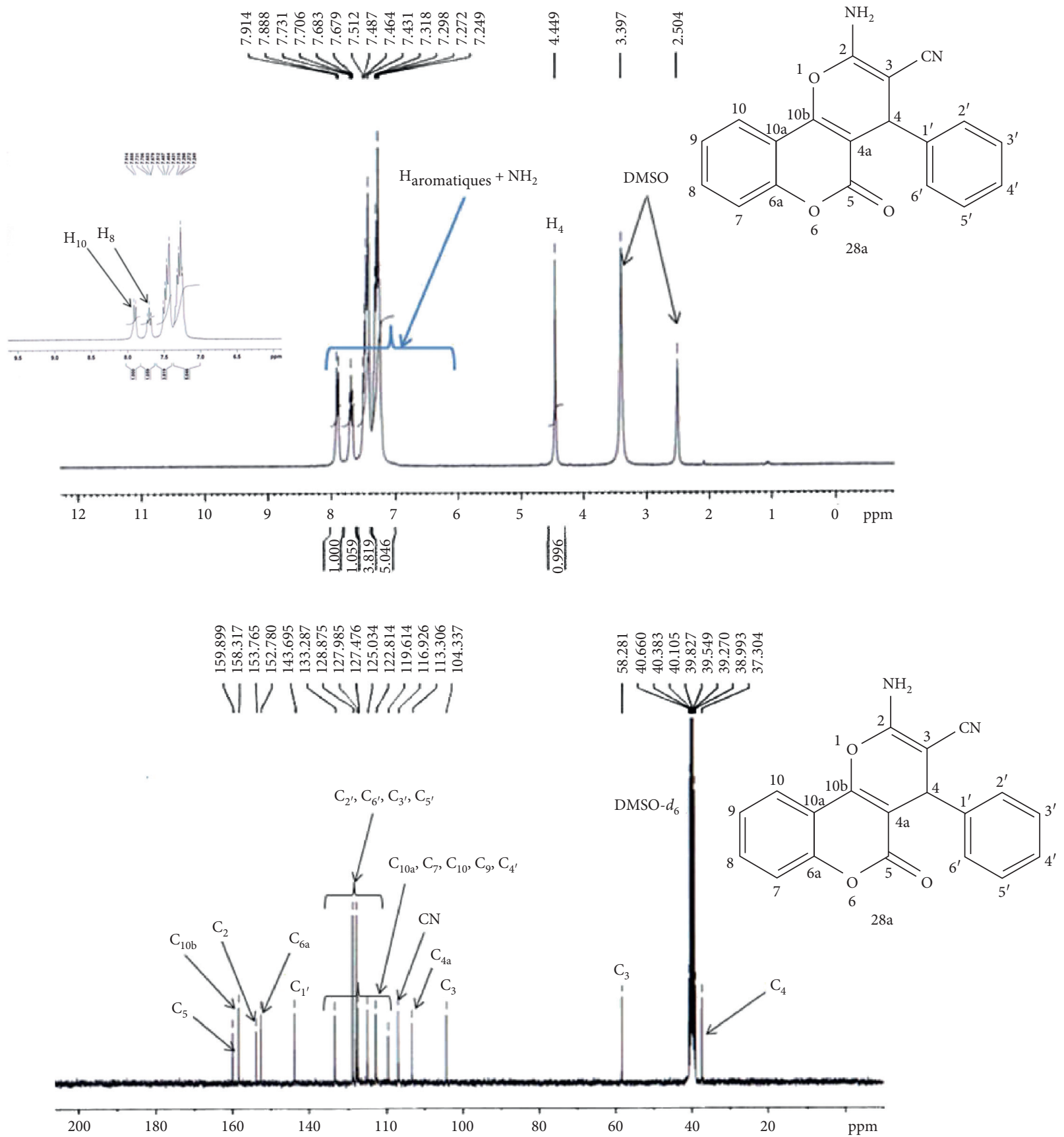

Figure 10: Experimental ${ }^{1} \mathrm{H}-\mathrm{NMR}$ and ${ }^{13} \mathrm{C}-\mathrm{NMR}$ chemical shift spectra of the Chrom-D compound. The atom numbering is given in the same figure.

2.10. Molecular Docking. Molecular docking simulation aims to predict the best binding configuration of a ligand to a macromolecular partner. It generates a number of possible conformations/orientations, i.e., poses, of the ligand within the protein binding site. The best pose ligands were selected on the basis of their best conformation that allows the lowest free binding energy [42]. iGEMDOCK explores an interactive interface for preparing the binding site and ligand docking status, postdocking analysis, monitoring the progress, ranking, and visualization of the screened compounds by combining the pharmacologic interactions and the energy-based scoring function $[43,44]$. The molecular docking has been performed to study the inhibitor activity of Chrom-D as a ligand against AChE enzymes. The inhibition of AChE has appeared as one of the most promising strategies for the AD treatment and plays a crucial role in the acetylcholine-mediated neurotransmission [45-48]. The structures of AChE enzymes (1B41, 1EVE, and 1BDT) are taken from the Protein Data Bank. Then, eventual cocrystallized ligands and water molecules have been removed. The best-docked poses having the lowest energy from a total of 10 poses for each enzyme are retained. Intermolecular 


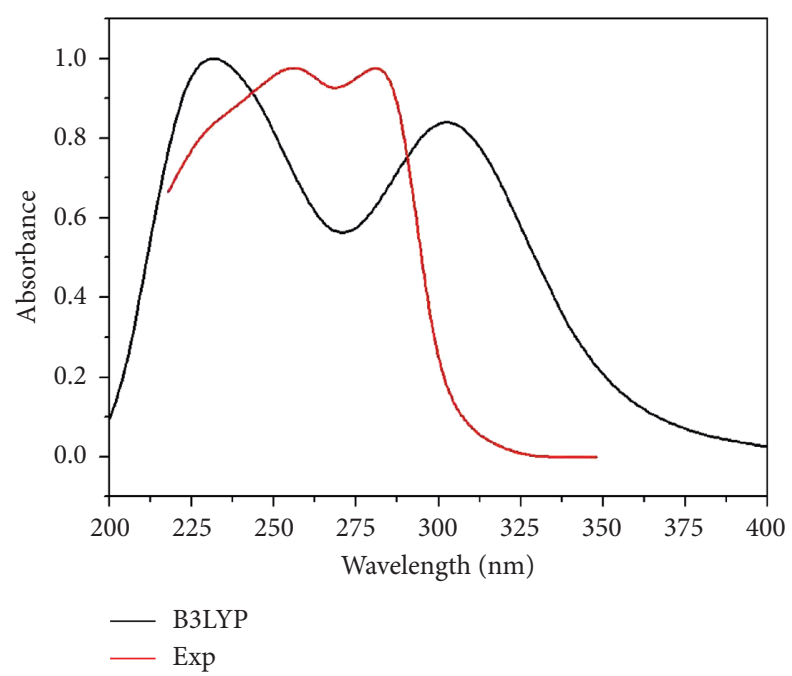

Figure 11: Experimental and predicted UV-vis spectra of the Chrom-D compound.

TABLE 4: Calculated absorption wavelengths $\lambda$, excitation energies $E$, and oscillator strengths $f$ using the TD-B3LYP/311++G(d,p) method in the DMSO solvent.

\begin{tabular}{|c|c|c|c|c|}
\hline No. & $E(\mathrm{eV})$ & $\lambda(\mathrm{nm})$ & $f(\mathrm{a} . \mathrm{u})$ & Major contribution \\
\hline 1 & 3.36 & 357 & 0.023 & $\mathrm{H} \longrightarrow \mathrm{L}(99 \%)$ \\
\hline 2 & 3.91 & 307 & 0.301 & $\mathrm{H}-1 \longrightarrow \mathrm{L}(93 \%)$ \\
\hline 3 & 4.07 & 295 & 0.026 & $\mathrm{H}-2 \longrightarrow \mathrm{L}(90 \%)$ \\
\hline 4 & 4.17 & 288 & 0.005 & $\mathrm{H}-3 \longrightarrow \mathrm{L}(90 \%)$ \\
\hline 5 & 4.33 & 277 & 0.085 & $\mathrm{H}-4 \longrightarrow \mathrm{L}(87 \%)$ \\
\hline 6 & 4.77 & 252 & 0.170 & $\mathrm{H} \longrightarrow \mathrm{L}+1(83 \%)$ \\
\hline 7 & 4.79 & 251 & 0.003 & $\mathrm{H}-6 \longrightarrow \mathrm{LUMO}(19 \%), \mathrm{H}-5 \longrightarrow \mathrm{L}(72 \%)$ \\
\hline 8 & 4.91 & 244 & 0.007 & $\mathrm{H} \longrightarrow \mathrm{L}+2(64 \%), \mathrm{H} \longrightarrow \mathrm{L}+3(27 \%)$ \\
\hline 9 & 4.95 & 242 & 0.045 & $\mathrm{H} \longrightarrow \mathrm{L}+2(29 \%), \mathrm{H} \longrightarrow \mathrm{L}+3(49 \%)$ \\
\hline 10 & 5.04 & 238 & 0.091 & $\mathrm{H} \longrightarrow \mathrm{L}+3(11 \%), \mathrm{H} \longrightarrow \mathrm{L}+4(40 \%), \mathrm{H} \longrightarrow \mathrm{L}+9(25 \%)$ \\
\hline 11 & 5.06 & 237 & 0.005 & $\mathrm{H}-1 \longrightarrow \mathrm{L}+1(73 \%)$ \\
\hline 12 & 5.15 & 233 & 0.007 & $\mathrm{H}-2 \longrightarrow \mathrm{L}+3(12 \%), \mathrm{H} \longrightarrow \mathrm{L}+6(11 \%), \mathrm{H} \longrightarrow \mathrm{L}+9(32 \%)$ \\
\hline 13 & 5.19 & 231 & 0.005 & $\mathrm{H} \longrightarrow \mathrm{L}+5(28 \%), \mathrm{H} \longrightarrow \mathrm{L}+6(40 \%)$ \\
\hline 14 & 5.22 & 230 & 0.035 & $\mathrm{H}-6 \longrightarrow \mathrm{L}(42 \%), \mathrm{H}-5 \longrightarrow \mathrm{L}(13 \%), \mathrm{H} \longrightarrow \mathrm{L}+6(15 \%)$ \\
\hline 15 & 5.26 & 228 & 0.015 & $\mathrm{H} \longrightarrow \mathrm{L}+4(25 \%), \mathrm{H} \longrightarrow \mathrm{L}+9(23 \%)$ \\
\hline 16 & 5.32 & 225 & 0.103 & $\mathrm{H}-1 \longrightarrow \mathrm{L}+2(50 \%)$ \\
\hline 17 & 5.36 & 224 & 0.054 & $\mathrm{H}-2 \longrightarrow \mathrm{L}+1(11 \%), \mathrm{H} \longrightarrow \mathrm{L}+5(35 \%), \mathrm{H} \longrightarrow \mathrm{L}+6(16 \%)$ \\
\hline 18 & 5.46 & 220 & 0.019 & $\mathrm{H}-2 \longrightarrow \mathrm{L}+1(42 \%), \mathrm{H}-1 \longrightarrow \mathrm{L}+3(41 \%)$ \\
\hline 19 & 5.52 & 217 & 0.085 & $\mathrm{H}-2 \longrightarrow \mathrm{L}+1(21 \%), \mathrm{H}-1 \longrightarrow \mathrm{L}+3(16 \%), \mathrm{H} \longrightarrow \mathrm{L}+5(12 \%)$ \\
\hline 20 & 5.58 & 215 & 0.031 & $\mathrm{H}-3 \longrightarrow \mathrm{L}+1(57 \%), \mathrm{H}-1 \longrightarrow \mathrm{L}+4(20 \%)$ \\
\hline
\end{tabular}

H: HOMO; L: LUMO.

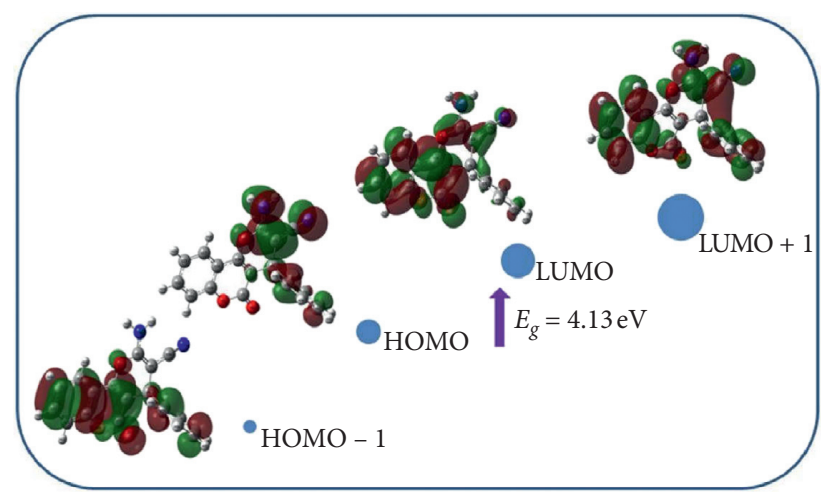

FIgURE 12: HOMO and LUMO frontier orbitals of the Chrom-D molecule. 
TABLE 5: TD-DFT/B3LYP/6-311++G(d,p) calculations of HOMO-LUMO energy gap, chemical potential, electronegativity, global hardness, global softness, electrophilicity index, and dipole moment performed in DMSO solvent within the IEFPCM model.

\begin{tabular}{lc}
\hline Function & Value \\
\hline$E_{\text {HOMO }}(\mathrm{eV})$ & -6.49 \\
$E_{\text {LUMO }}(\mathrm{eV})$ & -2.36 \\
$\Delta E_{\mathrm{HOMO}-\mathrm{LUMO} \text { gap }}(\mathrm{eV})$ & 4.13 \\
$E_{\mathrm{HOMO}-1}(\mathrm{eV})$ & -6.91 \\
$E_{\mathrm{LUMO+1}}(\mathrm{eV})$ & -1.03 \\
$\Delta E_{\mathrm{HOMO}-1-\mathrm{LUMO}+1 \mathrm{gap}}(\mathrm{eV})$ & 5.88 \\
Chemical potential $\mu(\mathrm{eV})$ & -4.43 \\
Electronegativity $\chi(\mathrm{eV})$ & 4.43 \\
Global hardness $\eta(\mathrm{eV})$ & 2.06 \\
Global softness $\zeta(\mathrm{eV})^{-1}$ & 0.24 \\
Global electrophilicity index $(\psi)$ & 4.75 \\
Dipole moment $($ debye $)$ & 11.03 \\
\hline
\end{tabular}
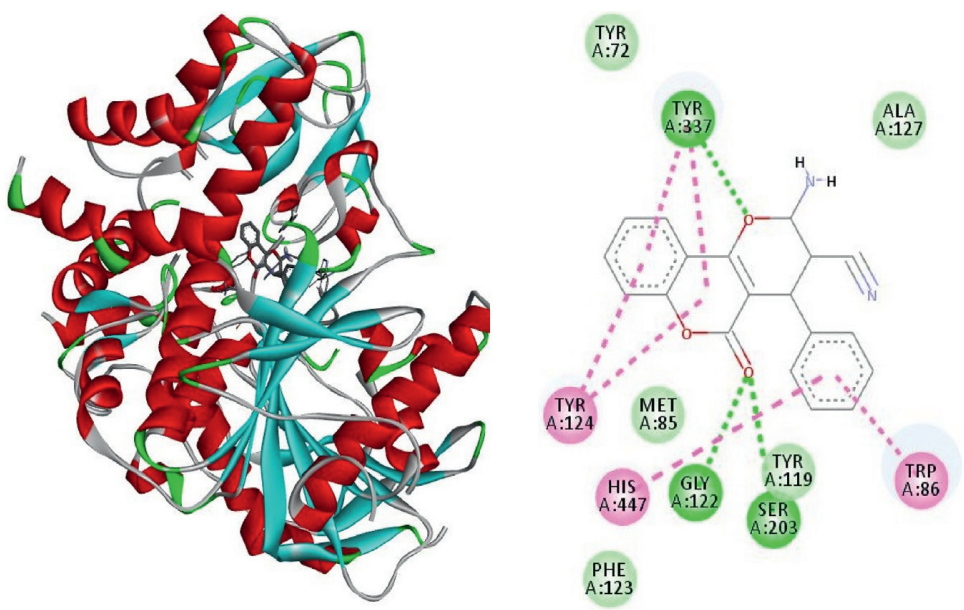

Interactions

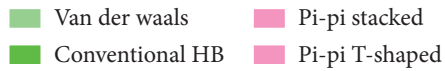

(a)
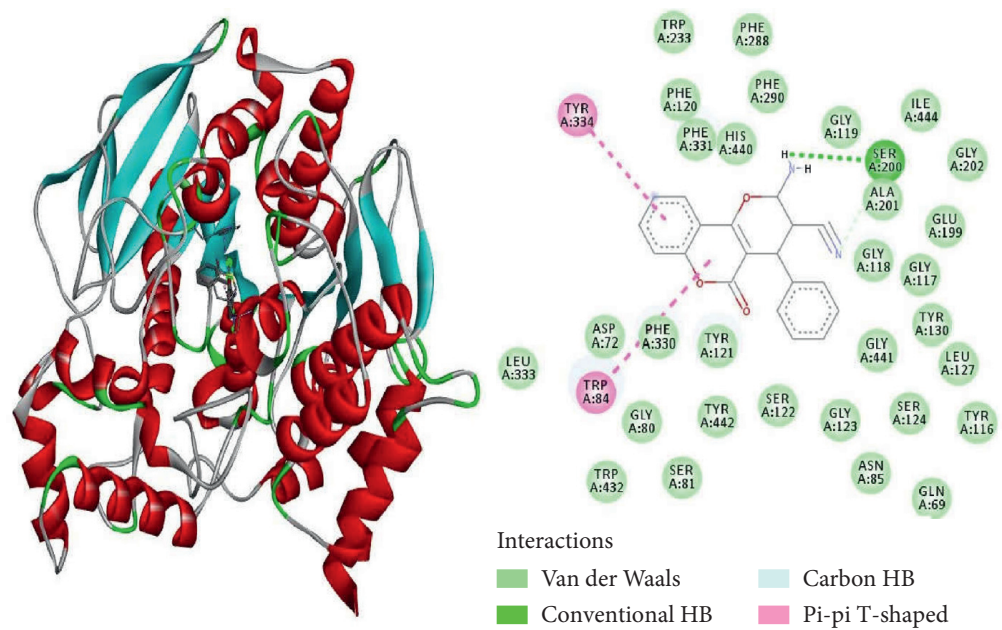

(b)

Figure 13: Continued. 

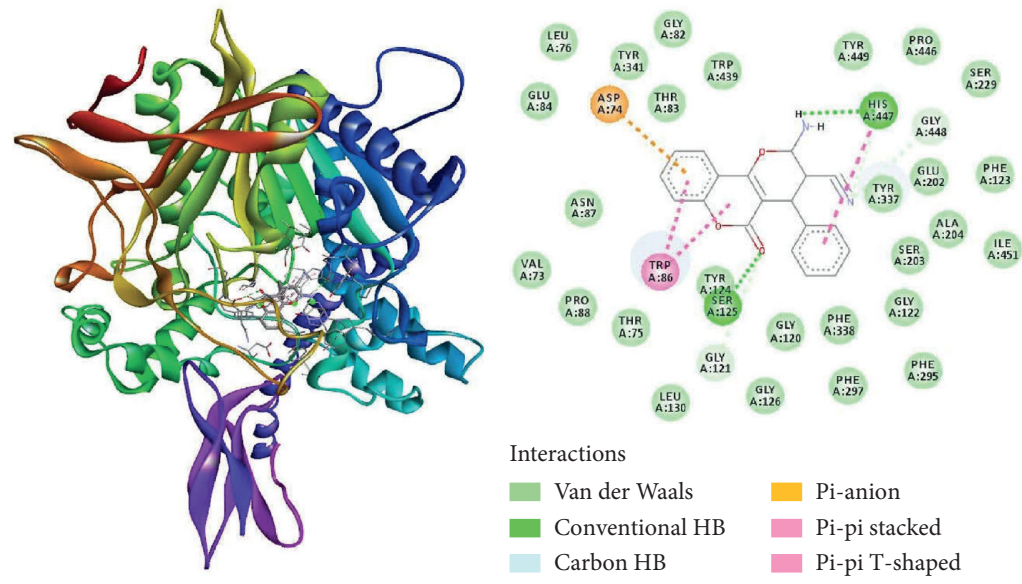

(c)

Figure 13: Best poses of the Chrom-D ligand in selected AChE enzymes along with ligand/enzyme interactions in 2D diagrams. (a) 1B41Chrom-D. (b) 1EVE-Chrom-D. (c) 1BDT-Chrom-D.

TABLE 6: Docking energies (in kcal.mol ${ }^{-1}$ ) of the compound Chrom-D against AChE enzymes.

\begin{tabular}{lcccc}
\hline Complex & Total energy & VdW energy & H-bonding energy & Binding affinity \\
\hline 1B41-Chrom-D & -123.0 & -109.3 & -13.7 & -8.3 \\
1EVE-Chrom-D & -116.2 & -104.8 & -11.4 & -11.1 \\
1BDT-Chrom-D & -115.1 & -104.5 & -10.6 & -7.8 \\
\hline
\end{tabular}

TABLE 7: Protein-Chrom-D contact interaction profile analysis. The energy values are given in kcal.mol ${ }^{-1}$.

\begin{tabular}{|c|c|c|c|c|c|c|}
\hline \multirow{8}{*}{ Chrom-D-1B41 } & $\mathrm{H}-\mathrm{M}$ & $\mathrm{H}-\mathrm{S}$ & $\mathrm{H}-\mathrm{S}$ & $\mathrm{H}-\mathrm{S}$ & V-M & V-S \\
\hline & GLY & TYR & SER & TYR & TRP & TRP \\
\hline & 122 & 24 & 203 & 337 & 86 & 86 \\
\hline & -3.5 & -2.5 & -2.5 & -2.5 & -4.2 & -19.2 \\
\hline & $\mathrm{V}-\mathrm{M}$ & V-S & V-S & V-S & V-S & V-S \\
\hline & GLY & SER & PHE & TYR & TYR & HIS \\
\hline & 121 & 125 & 297 & 337 & 341 & 447 \\
\hline & -10.7 & -4.4 & -4.9 & -13.9 & -6.0 & -5.0 \\
\hline Total energy & \multicolumn{6}{|c|}{-123.0} \\
\hline \multirow{8}{*}{ Chrom-D-1EVE } & $\mathrm{H}-\mathrm{S}$ & $\mathrm{H}-\mathrm{S}$ & V-S & V-M & V-M & V-S \\
\hline & GLU & SER & TRP & GLY & GLY & TYR \\
\hline & 199 & 200 & 84 & 117 & 118 & 121 \\
\hline & -3.5 & -5.9 & -13.6 & -6.7 & -11.9 & -5.0 \\
\hline & V-S & V-S & V-S & V-S & V-S & \\
\hline & PHE & PHE & PHE & TYR & HIS & \\
\hline & 290 & 330 & 331 & 334 & 440 & \\
\hline & -4.3 & -13.8 & -10.8 & -7.6 & -8.4 & \\
\hline Total energy & \multicolumn{6}{|c|}{-116.2} \\
\hline \multirow{9}{*}{ Total energy } & $\mathrm{H}-\mathrm{S}$ & H-M & V-M & V-S & V-M & V-S \\
\hline & SER & HIS & TRP & TRP & GLY & TYR \\
\hline & 125 & 447 & 86 & 86 & 121 & 124 \\
\hline & -3.9 & -3.5 & -6.1 & -34.0 & -4.7 & -4.7 \\
\hline & V-S & V-S & & & & \\
\hline & TYR & HIS & & & & \\
\hline & 337 & 447 & & & & \\
\hline & -11.2 & -8.4 & & & & \\
\hline & \multicolumn{6}{|c|}{-115.1} \\
\hline
\end{tabular}

interactions between amino acids of the binding site and Chrom-D, for the best-docked state, were visualized using Discovery Studio 2017 R2 Client software. The best poses of the ligand Chrom-D in the AChE enzymes along with ligand/enzyme interactions in 2D diagrams are plotted in Figure 13. The docking energies are listed in Table 6.

The ligand-enzyme interactions are mainly ensured by $\mathrm{VdW}$ and hydrogen-bonding types. Referring to the 
binding affinity values, 1EVE has the highest electronic interaction. Moreover, the results showed that 1B41 has the highest $\mathrm{VdW}$ interaction compared to $1 \mathrm{EVE}$ and $1 \mathrm{BDT}$ enzymes. The main interaction between the three enzymes and our studied compound is mainly ensured by $\mathrm{VdW}$ interactions. This result is confirmed by considerable binding affinity values. The calculated values of the interaction between the residue and the Chrom-D ligand are given in Table 7.

These results show that most of interactions are associated to TRP86 and for 1B41 and 1BDT with -19.2 and $-34.0 \mathrm{kcal} \mathrm{mol}^{-1}$, respectively, whereas the highest value was calculated for the interaction between PHE330 and 1EVE. The corresponding value is found to be $-13.8 \mathrm{kcal} \mathrm{mol}^{-1}$. These results point to a good inhibitor activity of our studied compound.

\section{Conclusion}

In this work, the structure of Chrom-D has been investigated using several experimental techniques, X-ray diffraction reported previously by Sharma et al., IR, NMR, and UV spectroscopy. Its molecular geometry has been optimized with DFT calculation. All intermolecular interactions taken place between different components of the molecule have been, deeply, discussed in terms of Hirshfeld surfaces and RDG to confirm the structural data. These techniques prove that the crystal structure is mainly stabilized through the hydrogen-bonding interactions between carbonyl of pyran rings and the amino groups of its adjacent neighbors. In the second part of this study, we identified the nucleophilic and electrophilic attacks through the calculation of MEP, Mulliken charge distribution, and Fukui functions. Then, the vibrational modes have been calculated and assigned to the experimental frequencies. Also, HOMO-LUMO gap energy calculated in the frame of the TD-DFT method was found to be $4.13 \mathrm{eV}$, which explains the charge transfer within the molecule. This relatively low HOMO-LUMO gap and the high value of the dipole moment $(11 \mathrm{D}$ in DMSO solvent) confirm the reactivity of the Chrom-D molecule. Besides, the calculated polarizability and first-order hyperpolarizability for the isolated molecule support the idea that the title compound is an excellent candidate for the fabrication of nonlinear optical (NLO) devices. Finally, the molecular docking simulation showed that Chrom-D has the potential to inhibit acetylcholinesterase.

3.1. Experimental Section. ${ }^{1} \mathrm{H}-\mathrm{NMR}(300 \mathrm{MHz})$ and ${ }^{13} \mathrm{C}$ NMR $(75 \mathrm{MHz})$ spectra were recorded in deuterated $\mathrm{CDCl}_{3}$ and DMSO- $\mathrm{d}_{6}$ using Bruker AC-300. All chemical shifts indexed as $\delta$ values (ppm) and coupling constants $(J)$ were expressed in Hz. At ambient temperature, the FT-IR spectrum was recorded as a $\mathrm{KBr}$ pellet using the Jasco $4100 \mathrm{FT}$-IR spectrophotometer. The UV-vis spectrum of our investigated compound was performed at $25^{\circ} \mathrm{C}$ in DMSO solvent using concentration equal to $5.10^{-5} \mathrm{M}$.
3.2. Computational Details. Starting from the X-ray structure determined by Sharma et al. [16], the geometry of Chrom-D is optimized in the ground state at the B3LYP/6$311++\mathrm{G}(\mathrm{d}, \mathrm{p})$ level of theory using Gaussian 09 program package [49]. The calculation is performed in DMSO solvent associated to the IEFPCM solvation model and without any constraint on the geometry. The results were visualized by using GaussView program [50]. The convergence to a global minimum of the optimized geometry is confirmed by the absence of imaginary frequency. The vibrational assignments have been performed on the basis of total energy distribution (TED) using VEDA4 program [51]. The Hirshfeld surfaces and the fingerprint 2D plots are generated by using CrystalExplorer 3.1 package $[18,19]$. The RDG function is plotted by means of Multiwfn [52] and VMD [53] programs. The UV-vis spectrum is calculated in the frame of the TD-DFT method at the same level of theory. The contributions of electronic transitions are identified with GaussSum program [54].

The docking simulations of Chrom-D as an acetylcholinesterase inhibitor against $\mathrm{AD}$ were made using two protocols. For the first one, the molecular docking between Chrom-D as a ligand and the AChE enzymes was carried out using iGEMDOCK software $[43,44]$. In the second one, we have used AutoDock Vina program [55]. The Discovery Studio 2017 R2 Client program was used for the preparation of enzymes and the visual representation of ligand-enzyme interactions in the best poses.

\section{Data Availability}

The data used to support the findings of this study are available from the corresponding author upon request.

\section{Disclosure}

The funders had no role in the design of the study; in the collection, analyses, or interpretation of the data; in the writing of the manuscript; or in the decision to publish the results.

\section{Conflicts of Interest}

The authors declare no conflicts of interest.

\section{Supplementary Materials}

The supplementary data contain Mulliken charge distribution, condensed Fukui functions, and the 2D fingerprint plots along with the percentage of contacts' contribution to the total Hirshfeld surface of the Chrom-D compound. (Supplementary Materials)

\section{References}

[1] A. R. Katritzky, C. W. Rccs, and E. F. V. Scriven, Comprehensive Heterocyclic Chemistry II, Elsevier, Amsterdam, Netherlands, 1996.

[2] W. A. L. Van Otterlo, E. L. Ngidi, S. Kuzvidza, G. L. Morgans, S. S. Moleele, and C. B. de Koning, "Ring-closing metathesis 
for the synthesis of $2 \mathrm{H}$ - and $4 \mathrm{H}$-chromenes, Tetrahedron, vol. 61, no. 42, pp. 9996-10006, 2005.

[3] T. Eichert, S. Hauptmann, and A. Speichcr, The Chemistry of Heterocycles: Structure, Reactions, Synthesis and Applications, Wiley, Hoboken, NJ, USA, 2nd edition, 2004.

[4] K. D. Barron, "The microglial cell. A historical review," Journal of the Neurological Sciences, vol. 134, pp. 57-68, 1995.

[5] M. L. Block and J.-S. Hong, "Microglia and inflammationmediated neurodegeneration: multiple triggers with a common mechanism," Progress in Neurobiology, vol. 76, no. 2, pp. 77-98, 2005.

[6] S. Lehnardt, L. Massillon, P. Follett et al., "Activation of innate immunity in the CNS triggers neurodegeneration through a Toll-like receptor 4-dependent pathway," Proceedings of the National Academy of Sciences, vol. 100, no. 14, pp. 8514-8519, 2003.

[7] K. N Venugopala, V. Rashmi, and B. Odhav, "Review on natural coumarin lead compounds for their pharmacological activity," BioMed Research International, vol. 2013, Article ID 963248, 14 pages, 2013.

[8] N. Thomas and S. M. Zachariah, "Pharmacological activities of chromene derivatives: an overview," Asian Journal of Pharmaceutical and Clinical Research, vol. 6, pp. 11-15, 2013.

[9] T. Suresh, V. Arunima, K. Atin, G. Sandeep, V. R. Prarthana, and R. K. Ganesh, "Novel chromeneimidazole derivatives as antifungal compounds: synthesis and in vitro evaluation," Acta Poloniae Pharmaceutica, vol. 67, pp. 423-427, 2010.

[10] S. J. Mohr, M. A. Chirigos, F. S. Fuhrman, and J. W. Pryor, "Pyran copolymer as an effective adjuvant to chemotherapy against a murine leukemia and solid tumor," Cancer Research, vol. 35, no. 12, pp. 3750-3754, 1975.

[11] C. K. Denish, K. P. Hetal, and K. G. Nilesh, "oxazol-3-yl) pyrano (3, 2-C) chromene-2, 5-dione," American Journal of Biomedical Research, vol. 2, pp. 126-130, 2012.

[12] M. M. Khafagy, A. H. F. Abd El-Wahab, F. A. Eid, and A. M. El-Agrody, "Synthesis of halogen derivatives of benzo [h]chromene and benzo[a]anthracene with promising antimicrobial activities," Il Farmaco, vol. 57, no. 9, pp. 715-722, 2002.

[13] W. O. Foye, Principi di ChemicoFarmaceutica, p. 416, Piccin: Pandora, Rome, Italy, 1991.

[14] C. S. Konkoy, D. B. Fick, S. X. Cai, N. C. Lan, and J. F. W. Keana, "Silica-grafted ionic liquids as recyclable catalysts for the synthesis of 3,4-Dihydropyrano[c]chromenes and Pyra-no[2,3-c]pyrazoles," Chemical Abstract, vol. 134, p. 29313a, 2001 PCT Int Appl WO 00751232000.

[15] Y. Bouazizi, A. Romdhane, and H. B. Jannet, "Synthesis of new 3,4-dihydropyrano[c]chromene derivatives and their evaluation as acetyl cholinesterase inhibitors," European Journal of Chemistry, vol. 5, no. 3, pp. 457-462, 2014.

[16] S. Sharma, G. Brahmachari, B. Banerjee, R. Kant, and V. K. Gupta, "Synthesis, characterization, and crystal structure of 2-amino-5-oxo-4-phenyl-4,5-dihydropyrano[3,2-c] chromene-3-carbonitrile," Crystallography Reports, vol. 60, no. 7, pp. 1142-1146, 2015.

[17] D.-Q. Shi, N. Wu, Q. Zhuang, and Y. Zhang, "2-Amino-4-(4methoxyphenyl)-5-oxo-4H,5H-pyrano[3,2-c]chromene-3carbonitrile N,N-dimethylformamide solvate," Acta Crystallographica Section E Structure Reports Online, vol. 60, no. 12, pp. o2359-o2361, 2004.

[18] M. A. Spackman and D. Jayatilaka, "Hirshfeld surface analysis," CrystEngComm, vol. 11, no. 1, pp. 19-32, 2009.

[19] M. A. Spackmann and D. Jayatilaka, "Towards quantitative analysis of intermolecular interactions with Hirshfeld surfaces," Chemical Communications, vol. 37, pp. 3814-3816, 2007.

[20] E. R. Johnson, S. Keinan, P. Mori-Sánchez, J. ContrerasGarcia, A. J. Cohen, and W. Yang, "Revealing noncovalent interactions," Journal of the American Chemical Society, vol. 132, no. 18, pp. 6498-6506, 2010.

[21] B. Kosar and C. Albayrak, "Spectroscopic investigations and quantum chemical computational study of (E)-4-methoxy-2[(p-tolylimino)methyl]phenol," Spectrochimica Acta Part A: Molecular and Biomolecular Spectroscopy, vol. 78, no. 1, pp. 160-167, 2011.

[22] N. Okulik and A. H. Jubert, "Theoretical analysis of the reactive sites of non-steroidal anti-inflammatory drugs, Internet Electron," Journal of Molecular Design, vol. 4, pp. 17-30, 2005.

[23] E. Scrocco and J. Tomasi, "Electronic molecular structure, reactivity and intermolecular forces: an euristic interpretation by means of electrostatic molecular potentials," Advances in Quantum Chemistry, vol. 11, pp. 115-193, 1978.

[24] F. J. Luque, J. M. López, and M. Orozco, "Perspective on "Electrostatic interactions of a solute with a continuum. A direct utilization of $\mathrm{ab}$ initio molecular potentials for the prevision of solvent effects"," Theoretical Chemistry Accounts: Theory, Computation, and Modeling (Theoretica Chimica Acta), vol. 103, no. 3-4, pp. 343-345, 2000.

[25] P. Geerlings, F. De Proft, and W. Langenaeker, "Conceptual density functional theory," Chemical Reviews, vol. 103, no. 5, pp. 1793-1874, 2003.

[26] R. G. Parr and W. Yang, "Density functional approach to the frontier-electron theory of chemical reactivity," Journal of the American Chemical Society, vol. 106, no. 14, pp. 4049-4050, 1984.

[27] P. W. Ayers, W. Yang, and L. J. Bartolotti, "Fukui function," in Chemical Reactivity Theory. A Density Functional View, P. K. Chattaraj, Ed., pp. 255-267, CRC Press, New York, NY, USA, 2009.

[28] C. Morell, A. Grand, S. Gutiérrez-Oliva, and A. Toro-Labbé, "Chapter 7 Using the reactivity-selectivity descriptor $\Delta f(r)$ in organic chemistry," Theoretical and Computational Chemistry, vol. 19, pp. 101-117, 2007.

[29] P. Fuentealba, E. Florez, and W. Tiznado, "Topological analysis of the Fukui function," Journal of Chemical Theory and Computation, vol. 6, no. 5, pp. 1470-1478, 2010.

[30] T. B. Issa, H. Ghalla, S. Marzougui, and L. Benhamada, "Crystal structure and theoretical studies on quinoline phosphate," Journal of Molecular Structure, vol. 1150, pp. 127-134, 2017.

[31] H. Ghalla, N. Issaoui, M. Govindarajan, H. T. Flakus, M. H. Jamroz, and B. Oujia, "Spectroscopic and molecular structure investigation of 2-furanacrylic acid monomer and dimer using HF and DFT methods," Journal of Molecular Structure, vol. 1059, pp. 132-143, 2014.

[32] G. Socrates, Infrared and Raman Characteristic Group Frequencies: Tables and Charts, John Wiley \& Sons, Hoboken, NJ, USA, 2004.

[33] S. K. Gangwar, A. Kumar, A. K. Srivastava, N. Misra, and R. B. Singh, "Combined experimental and quantum chemical analysis of 2-(4-chlorophenyl)-2-(4-fluorophenylamino) acetonitrile," Organic and Biomolecular Chemistry, vol. 4, pp. 286-301, 2016.

[34] T. Schlick, Molecular Modeling and Simulation: An Interdisciplinary Guide, Springer \& Business Media, Berlin, Germany, Second edition, 2010.

[35] H. Fliegl, O. Lehtonen, D. Sundholm, and V. R. I. Kaila, "Hydrogen-bond strengths by magnetically induced 
currents," Physical Chemistry Chemical Physics, vol. 13, no. 2, pp. 434-437, 2011.

[36] G. Monaco, P. D. Porta, M. Jabłoński, and R. Zanasi, "Topology of the magnetically induced current density and proton magnetic shielding in hydrogen bonded systems," Physical Chemistry Chemical Physics, vol. 17, no. 8, pp. 5966-5972, 2015.

[37] A. Rauk, Orbital Interaction Theory of Organic Chemistry p. 86, 2nd edition, Wiley-Interscience, Hoboken, NJ, USA, 2001.

[38] A. Streitwieser Jr., Molecular Orbital Theory for Organic Chemists, Wiley, Hoboken, NJ, USA, 1961.

[39] B. J. Powell, T. Baruah, N. Bernstein et al., "A first-principles density-functional calculation of the electronic and vibrational structure of the key melanin monomers," The Journal of Chemical Physics, vol. 120, no. 18, pp. 8608-8615, 2004.

[40] H. Ghalla, N. Issaoui, F. Bardak, and A. Atac, "Intermolecular interactions and molecular docking investigations on 4methoxybenzaldehyde," Computational Materials Science, vol. 149, pp. 291-300, 2018.

[41] P. N. Prasad and D. J. Williams, Introduction to Nonlinear Optical Effects in Molecules and Polymers, Wiley, Hoboken, NJ, USA, 1991.

[42] M. Kandeel and Y. Kitade, "Computational analysis of siRNA recognition by the Ago2 PAZ domain and identification of the determinants of RNA-induced gene silencing," PLoS One, vol. 8, Article ID e57140, 2013.

[43] J.-M. Yang and C.-C. Chen, "GEMDOCK: a generic evolutionary method for molecular docking," Proteins: Structure, Function, and Bioinformatics, vol. 55, no. 2, pp. 288-304, 2004.

[44] C. H. Kai, F. C. Yen, R. L. Shen, and M. Y. Jinn, "iGEMDOCK: a graphical environment of enhancing GEMDOCK using pharmacological interactions and post-screening analysis," BMC Bioinformatics, vol. 12, p. S33, 2011.

[45] I. Silman and J. L. Sussman, "Acetylcholinesterase: "classical" and "non-classical" functions and pharmacology," Current Opinion in Pharmacology, vol. 5, no. 3, pp. 293-302, 2005.

[46] L. E. Hebert, P. A. Scherr, J. L. Bienias, D. A. Bennett, and D. A. Evans, "Alzheimer disease in the US population," Archives of Neurology, vol. 60, no. 8, pp. 1119-1122, 2003.

[47] P. T. Francis, A. M. Palmer, M. Snape, and G. K. Wilcock, "The cholinergic hypothesis of Alzheimer's disease: a review of progress," Journal of Neurology, Neurosurgery \& Psychiatry, vol. 66, no. 2, pp. 137-147, 1999.

[48] T. B. Issa, F. Sayari, H. Ghalla, and L. Benhamada, "Synthesis, crystal structure, DFT calculations and molecular docking of L-pyroglutamic acid," Journal of Molecular Structure, vol. 1178, pp. 436-449, 2019.

[49] M. J. Frisch, G. W. Trucks, H. B. Schlegel et al., Gaussian 09, Revision D. 01, Gaussian, Inc., Wallingford, CT, USA, 2010.

[50] R. I. Dennington, T. Keith, and J. Millam, GaussView, Version 5.0.8, Semichem Inc., Shawnee, KS, USA, 2008.

[51] M. H. Jamróz, "Vibrational energy distribution analysis (VEDA): scopes and limitations," Spectrochimica Acta Part A: Molecular and Biomolecular Spectroscopy, vol. 114, pp. 220230, 2013.

[52] T. Lu and F. Chen, "Multiwfn: a multifunctional wavefunction analyzer," Journal of Computational Chemistry, vol. 33, no. 5, pp. 580-592, 2012.

[53] W. Humphrey, A. Dalke, and K. Schulten, "VMD: visual molecular dynamics," Journal of Molecular Graphics, vol. 14, no. 1, pp. 33-38, 1996.
[54] N. M. O’Boyle, A. L. Tenderholt, and K. M. Langner, "cclib: a library for package-independent computational chemistry algorithms," Journal of Computational Chemistry, vol. 29, no. 5, pp. 839-845, 2008.

[55] O. Trott, A. J. Olson, and A. D. Vina, "Improving the speed and accuracy of docking with a new scoring function, efficient optimization and multithreading," Journal of Computational Chemistry, vol. 31, pp. 455-461, 2010. 